\title{
Poly (ADP-Ribose) Polymerase-1 (PARP-1) Induction by Cocaine Is Post-Transcriptionally Regulated by miR-125b
}

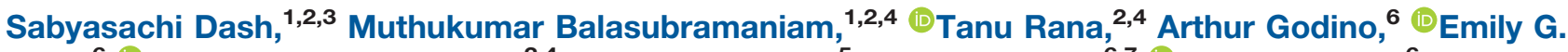 \\ Peck, ${ }^{6}$ (1) Jeffery Shawn Goodwin, ${ }^{2,4}$ Fernando Villalta, ${ }^{5}$ Erin S. Calipari,, ${ }^{6,7}$ (E) Eric J. Nestler, ${ }^{6}$ \\ Chandravanu Dash,, ${ }^{1,2,4}$ and Jui Pandhare
}

DOI:http://dx.doi.org/10.1523/ENEURO.0089-17.2017

${ }^{1}$ Center for AIDS Health Disparities Research, Meharry Medical College, Nashville, TN 37208, ${ }^{2}$ Center for Molecular and Behavioral Neuroscience, Meharry Medical College, Nashville, TN 37208, ${ }^{3}$ School of Graduate Studies and Research, Meharry Medical College, Nashville, TN 37208, ${ }^{4}$ Department of Biochemistry and Cancer Biology, Meharry Medical College, Nashville, TN 37208, ${ }^{5}$ Department of Microbiology and Immunology, Meharry Medical College, Nashville, TN 37208, ${ }^{6}$ Department of Pharmacology, Vanderbilt University Medical Center, Nashville, TN 37232, and ${ }^{7}$ Fishberg Department of Neuroscience and Friedman Brain Institute, Icahn School of Medicine at Mount Sinai, New York, NY 10029

\begin{abstract}
Cocaine exposure alters gene expression in the brain via methylation and acetylation of histones along with methylation of DNA. Recently, poly (ADP-ribose) polymerase-1 (PARP-1) catalyzed PARylation has been reported as an important regulator of cocaine-mediated gene expression. In this study, we report that the cellular microRNA "miR-125b" plays a key role for cocaine-induced PARP-1 expression. Acute and chronic cocaine exposure resulted in the downregulation of miR-125b concurrent with upregulation of PARP-1 in dopaminergic neuronal cells and nucleus accumbens (NAc) of mice but not in the medial prefrontal cortex (PFC) or ventral tegmental area (NTA). In silico analysis predicted a binding site of miR-125b in a conserved 3'-untranslated region (3'UTR) of the PARP-1 mRNA. Knockdown and overexpression studies showed that miR-125b levels negatively correlate with PARP-1 protein expression. Luciferase reporter assay using a vector containing the 3'UTR of PARP-1 mRNA confirmed regulation of PARP-1 by miR-125b. Specific nucleotide mutations within the binding site abrogated miR-125b's regulatory effect on PARP-1 3'UTR. Finally, we established that downregulation of miR-125b and concurrent upregulation of PARP-1 is dependent on binding of cocaine to the dopamine transporter (DAT). Collectively, these results identify miR-125b as a post-transcriptional regulator of PARP-1 expression and establish a novel mechanism underlying the molecular effects of cocaine action.
\end{abstract}

Key words: PARP-1; PARylation; cocaine; miRNA; post-transcriptional regulation

\section{Significance Statement}

Poly (ADP-ribose) polymerase-1 (PARP-1) plays critical roles in neuronal function. Recently, PARP-1 and PARylation have been described as a novel regulator of cocaine addiction and reward. However, the cellular pathways and mechanisms that regulate PARP-1 expression in neurons are unknown. We have identified that the cellular miRNA "miR-125b" negatively regulates PARP-1 protein expression. In addition, we have established that cocaine-induced upregulation of PARP-1 is dependent on miR-125b expression. These results elucidate the mechanism of PARP-1 regulation by cocaine and uncover a novel pathway for the cellular and molecular effects of cocaine.

\section{Introduction}

Cocaine increases dopaminergic neurotransmission in key regions of brain and causes alterations in gene ex-

Received March 18, 2017; accepted July 17, 2017; First published August 7, 2017.

The authors declare no competing financial interests. pression that play critical roles in reward and addiction (Ritz et al., 1987; Nestler, 2004; Kalivas, 2007). Cocaine exposure regulates gene expression by inducing chroma- 
tin remodeling via acetylation, methylation, and phosphorylation of histones and methylation of DNA (Chao and Nestler, 2004). Additionally, post-transcriptional regulation of gene expression by cellular microRNAs (miRNA) has also been reported for cocaine action (Picciotto, 2010; Eipper-Mains et al., 2011; Xu et al., 2013). Recently, poly ADP-ribosylation (PARylation) of chromatin by PAR polymerase-1 (PARP-1) has been described as a novel chemical modification for the long-term effects of cocaine (Scobie et al., 2014). PARP-1 catalyzes the synthesis of the negatively charged polymer PAR on specific amino acids of target proteins (Krishnakumar and Kraus, 2010). Accordingly, PARylation of histones has been shown to regulate gene expression via decondensation of chromatin (Fontan-Lozano et al., 2010; Verdone et al., 2015).

PARP-1 is a DNA damage sensor (Wei and Yu, 2016) and plays important roles in the normal function and diseased conditions of brain ( $\mathrm{Ha}$ and Snyder, 2000; Cohen-Armon et al., 2004; Barr and Conley, 2007). PARP1-mediated PARylation plays key roles in learning and memory (Cohen-Armon et al., 2004; Fontan-Lozano et al., 2010; Wang et al., 2012). Recently, it has also been reported that PARP-1 and PARylation are involved in cocaine-induced molecular, neural, and behavioral plasticity (Scobie et al., 2014). For example, chronic exposure to cocaine induced expression and activity of PARP-1 in the nucleus accumbens (NAc), a key brain reward region, of rodents. Importantly, cocaine-induced PARP-1 expression enhanced transcription of genes that are important in synaptic formation and dendritic plasticity (Scobie et al., 2014). These findings and others illustrate the important functions of PARP-1 and PARylation in addiction and reward. However, the mechanism and the cellular pathways that regulate PARP-1 in neurons are not identified. Several studies report transcriptional regulation of PARP-1 expression, since PARP-1 promoter sequences of human, mice and rat contain binding sites of transcriptional factors, including Sp1, YY1, AP-2, ETS, and NF-1 (Oei et al., 1997; Hassa and Hottiger, 1999; Zaniolo et al., 2007; Doetsch et al., 2012). Additionally, there are two reports suggesting post-transcriptional regulation of PARP-1 expression. In cancer cell models, the cellular miRNA "miR124" has been shown to regulate PARP-1 (Chen et al., 2015), whereas miR-223 expression was negatively cor-

analyzed data; C.D. and J.P. wrote the paper.

This work was partly supported by National Institutes of Health (NIH) Grants DA037779 (to J.P.), DA024558, DA30896, DA033892, DA021471, and Al22960 (to C.D.), DA008227 (to E.J.N.), and DA042111 (to E.S.C.). We work was also supported by the RCMI Grant G12MD007586, the Vanderbilt CTSA Grant UL1RR024975, the Meharry Translational Research Center (MeTRC) CTSA grant (U54 RR026140 from NCRR/NIH, the U54 Grant MD007593 from NIMHD/NIH, and the Tennessee Center for AIDS Research (P30 Al110527).

Correspondence should be addressed to either of the following: Jui Pandhare, Ph.D., Old Hospital Building-CAHDR, Room 5023, 1005 Dr. DB Todd Jr Boulevard, Nashville, TN 37208, E-mail: jpandhare@mmc.edu; or Chandravanu Dash, Ph.D., Old Hospital Building-CAHDR, Room 5027, 1005 Dr. DB Todd Jr Boulevard, Nashville, TN 37208, E-mail: cdash@mmc.edu.

DOI:http://dx.doi.org/10.1523/ENEURO.0089-17.2017

Copyright $\odot 2017$ Dash et al.

This is an open-access article distributed under the terms of the Creative Commons Attribution 4.0 International license, which permits unrestricted use, distribution and reproduction in any medium provided that the original work is properly attributed. related with PARP-1 levels (Meloche et al., 2015). Surprisingly, regulation of PARP-1 gene expression in neuronal cells remains largely obscure.

We have identified miR-125b as a key posttranscriptional regulator of PARP-1 expression in neuronal cells. miR-125b is a highly conserved cellular miRNA (Lagos-Quintana et al., 2002) that regulates a network of genes involved in neuronal differentiation and function (Le et al., 2009). Our results show that acute and chronic cocaine exposure resulted in the downregulation of miR$125 \mathrm{~b}$ concurrent with upregulation of PARP-1 in a dopaminergic neuronal cell model. Additionally, cocaine treatment resulted in the reduction in miR-125b levels and induction of PARP-1 in NAc of mice but not in medial prefrontal cortex (PFC) or ventral tegmental area (VTA). In silico analysis identified a binding site of miR-125b in the 3'-untranslated region (3'UTR) of PARP-1 mRNA that is conserved in various mammalian species. Knockdown and overexpression experiments demonstrate that PARP-1 expression is negatively correlated with miR-125b levels. Luciferase reporter assay show that miR-125b expression negatively regulates the activity of PARP-1 3'UTR and site directed mutagenesis confirm the direct binding of miR$125 \mathrm{~b}$ to the PARP-1 3'UTR. Finally, we define that cocaine's effect on miR-125b/PARP-1 axis is dependent on its binding to dopamine transporter (DAT). These studies establish that miR-125b is a key post-transcriptional regulator of PARP-1 in neurons.

\section{Materials and Methods}

\section{Reagents}

Cocaine hydrochloride, all-trans-retinoic acid (ATRA), and nomifensine were purchased from Sigma-Aldrich. Anti-PARP-1 and anti-caspase-9 antibodies were from Cell Signaling Technology, anti-DAT and anti-tyrosine hydroxylase (TH) antibodies were purchased from Abcam and anti-GAPDH and anti- $\beta$ actin antibodies were procured from Sigma-Aldrich.

\section{Cell culture and cocaine treatment}

Human neuroblastoma cell line (SH-SY5Y) was purchased from American type Culture Collection and was maintained in a 1:1 mixture of DMEM and Ham's F12 medium (Gibco) supplemented with 10\% (v/v) heatinactivated fetal bovine serum (FBS; Gibco), 2 mM glutamine, and $1 \%$ antibiotics (penicillin-streptomycin) at $37^{\circ} \mathrm{C}$ in a humidified $5 \% \mathrm{CO}_{2}$ atmosphere. For differentiation, the maintenance media was replaced with serumfree medium supplemented with ATRA at a final concentration of $10 \mu \mathrm{M}$ and the cells were cultured for 4-6 d with change of media every alternate day. In all the experiments, appropriate number of SH-SY5Y cells were seeded and after differentiation, treated with cocaine in a dose-dependent manner from $1 \mu \mathrm{M}$ to $100 \mu \mathrm{M}$. These concentrations were used based on published literature that highlight their physiologic relevance (Van Dyke et al., 1976; Mittleman and Wetli, 1984; Peretti et al., 1990; Karch et al., 1998; Blaho et al., 2000; Heard et al., 2008). The HEK-293T cells with stable expression of YFP-tagged DAT was grown and maintained in DMEM supplemented 
with $10 \%(\mathrm{v} / \mathrm{v})$ heat-inactivated FBS, $2 \mathrm{mM}$ glutamine, and $1 \%$ antibiotics (penicillin-streptomycin) at $37^{\circ} \mathrm{C}$ and $5 \%$ $\mathrm{CO}_{2}$. For acute treatment, cells were treated with cocaine overnight, whereas for chronic treatment, cells were exposed to cocaine once daily for $7 \mathrm{~d}$.

\section{Phase contrast microscopy}

SH-SY5Y cells were cultured and maintained in serum free-differentiation medium for $5 \mathrm{~d}$ on collagen coated six-well plates. Phenotypic changes were observed and monitored under bright field microscope. The differentiation was assessed by changes compatible with neuronlike morphology and neurite outgrowth from the cell body. Neurite extensions on captured images were measured using ImageJ 2.0 software $(\mathrm{NIH})$ and lengths of individual neurites were calculated in pixels. Calculated values of neurite lengths were plotted as an average of field views for each sample $(n=10)$.

\section{Immunostaining and confocal microscopy}

SH-SY5Y cells were seeded and differentiated on collagen coated glass coverslips. After differentiation the cells were fixed with $3.7 \%$ formaldehyde in PBS $(1 \times)$ for 30 min, washed two times in PBS $(1 \times)$ followed by blocking/permeabilization in a solution of PBS $(1 \times)$ containing $10 \%$ FBS and $0.1 \%$ Triton $\mathrm{X}-100$ for $30 \mathrm{~min}$ at room temperature. The cells were then stained at room temperature for $30 \mathrm{~min}$ with rat anti-DAT [1:200] and rabbit anti-TH (1:1500) prepared in blocking/permeabilization solution. Following incubation, the cells were washed three times with PBS $(1 \times)$ for 5 min and then incubated with secondary antibodies such as chicken anti-rat IgG Alexa Fluor 488 conjugate and donkey anti-rabbit IgG Alexa Fluor 546, prepared in blocking/permeabilization solution, respectively, at room temperature for $30 \mathrm{~min}$. The cells were then washed three times with PBS $(1 \times)$ and mounted with ProLong Gold Antifade reagent with DAPI (Life Technologies) for nuclear staining on to glass slides. Confocal images were acquired using a Nikon TE2000-U laser-scanning confocal microscope, and data analysis was performed with NIS-Elements AR software (Nikon).

\section{Real-time PCR analysis}

For measuring miRNA expression, total RNA was isolated by using miRNeasy mini kit (QIAGEN) as per manufacturer's instructions. The cDNA was synthesized from the isolated total RNA using the miRCURY LNA Universal RT cDNA Synthesis kit (Exiqon). SYBR Green-based quantitative real-time PCR (qPCR) was used to quantify miR-125b or 5s ribosomal RNA (5srRNA) in a reaction mixture containing $50 \mathrm{ng}$ of the CDNA as template and $300 \mathrm{nM}$ LNA-based primers specific for miR-125b and 5srRNA (Exiqon). qPCR assay was performed in a C1000 Touch CFX96 system (Bio-Rad) as per manufacturer's instructions. The expression levels (Ct values) of miR$125 \mathrm{~b}$ are normalized to expression levels of $5 \mathrm{~s}$ rRNA as $\Delta \mathrm{Ct}$ values. For multiple samples involving untreated control and treated samples, the relative expression levels of miR-125b is expressed as $2-\Delta$ Ct values by comparing the $\Delta \mathrm{Ct}$ values of untreated control to the treated samples.
Fold change in miR-125b expression was calculated by comparing the 2- $\Delta$ Ct values of the treated sample with that of untreated control.

For measuring PARP-1 mRNA expression, total RNA was isolated from untreated- and cocaine-treated cells and tissues using RNAesy Mini kit (QIAGEN) and cDNA synthesis was conducted using iScript cDNA synthesis kit (Bio-Rad). qPCR assay was performed by subjecting 50 ng of cDNA to iTaq Universal SYBR Green chemistry (Bio-Rad) using primers specific for PARP-1 (forward: 5'-GAGGTGGATGGGTTCTCTGA-3' and reverse: 5'ACACCCCTTGCACGTACTTC-3') and GAPDH (forward: 5'-GAAGGTGAAGGTCGGAGTC-3' and reverse: 5'GAAGATGGTGATGGGATTTC-3') as per manufacturer's instructions. The expression levels of PARP-1 mRNA were normalized to that of GAPDH mRNA levels. Relative expression of PARP-1 mRNA in untreated control and treated samples is expressed as $2-\Delta \mathrm{Ct}$ values as described previously and fold changes are calculated by comparing the 2- $\Delta$ Ct values of the treated sample with that of untreated control.

\section{Bioinformatics analysis}

Prediction of miR-125b binding sites in the 3'UTR of the $P A R P-1$ gene was conducted by submitting the miR-125b sequence and 3'UTR sequence of the PARP-1 gene (Genbank accession number: NM_001618.3) to RNAhybrid 2.1 (Rehmsmeier et al., 2004) using default parameters. RNAhybrid analysis revealed three putative miR-125b binding sites in the PARP-1 3'UTR based on sequence match and predicted secondary structures. The putative targets obtained were further analyzed for sequence conservation across mammalian species using Clustal Omega multiple sequence alignment program (Sievers et al., 2011). The sequence with the highest identity $(>90 \%)$ highlighted its functional significance and was chosen for further analyses in this study.

\section{Western blotting}

SH-SY5Y cells were treated with various concentrations of cocaine for $24 \mathrm{~h}$, after which the cells were harvested and washed with PBS $(1 \times)$. Cell lysates were prepared using standard protocol and total protein concentrations were quantified by BCA protein assay (Pierce). Equal amounts of total protein from cell lysates were electrophoresed on SDS-polyacrylamide gels and transferred to nitrocellulose membranes using a semidry blotter (Bio-Rad). Membranes were blocked with 5\% (w/v) nonfat milk in Tris-buffered saline (TBS; pH 8.0; Sigma). Blots were then probed with the primary antibody in blocking buffer, and subsequently by a secondary antibody conjugated to horseradish peroxidase $(1: 2000)$. All blots were washed in TBS with Tween 20 (pH 8.0; Sigma) and developed using the enhanced chemiluminescence (ECL) procedure (Pierce). Blots were routinely stripped by treating with Restore Plus stripping buffer (Pierce) and reprobed with anti-GAPDH or anti- $\beta$-actin monoclonal antibodies (Sigma) to serve as loading controls. Antirabbit antibody (Santa Cruz) was used as secondary antibody. Densitometry analyses were performed using LI- 
COR Image Studio version 5.2 software (LI-COR). Data were normalized to levels of GAPDH or $\beta$-actin.

\section{Flow cytometry}

Neuronal apoptosis was determined by flow cytometry using the fluorescein isothiocyanate (FITC)-conjugated Annexin V apoptosis kit (Beckman Coulter) according to the manufacturer's instructions. Untreated and cocainetreated SH-SY5Y cells $\left(1 \times 10^{6}\right)$ were washed in $1 \times$ annexin binding buffer and incubated for $15 \mathrm{~min}$ with Annexin V (AV)-FITC at $4^{\circ} \mathrm{C}$. After two washes with binding buffer, propidium iodide (PI; $100 \mu \mathrm{g} / \mathrm{mL})$ was added. Thereafter, cells were immediately analyzed by flow cytometry using FACSCalibur (Becton Dickinson). Positive staining of the plasma membrane with $\mathrm{AV}$ and lack of concomitant staining of nuclei with PI was measured as apoptosis at an early stage, whereas positive staining of cells with both AV and PI was indicative of apoptosis at later stages.

\section{Knockdown and overexpression of miR-125b in SH-SY5Y cells}

miR-125b inhibitors/mimics and controls were purchased from GE-Dharmacon. Differentiated SH-SY5Y cells $\left(2 \times 10^{5}\right.$ cells/well) grown in six-well culture plates were transfected with $100-300 \mathrm{pM}$ anti-miRNAs/mimics or scrambled controls using Lipofectamine 3000 (Life Technologies). After transfection, cells were incubated for $48 \mathrm{~h}$ at $37^{\circ} \mathrm{C} / 5 \% \mathrm{CO}_{2}$, washed with PBS $(1 \times)$, and harvested by gentle scraping for RNA and protein isolation.

\section{Luciferase assay}

The luciferase reporter plasmid containing the fulllength (763 nt) 3'UTR region of the PARP-1 gene (Genbank accession number: NM_001618.3) cloned downstream of the luciferase ORF in the pMirTarget vector (pPARP-3'UTR) was obtained from OriGene Technologies. To generate the control plasmid (pPARP-Null), the PARP-1 3'UTR insert was removed from pPARP-3'UTR by restriction digestion and the linearized plasmid was blunted using Klenow Polymerase (NEB) and subsequently religated using T4 DNA ligase (Promega). For mutating miR-125b binding site in the PARP-1 3'UTR (pPARP-3'UTRMut), we conducted site-directed mutagenesis using the QuikChange II XL Site-Directed Mutagenesis kit (Agilent Technologies) as per manufacturer's protocol. Differentiated SH-SY5Y cells $\left(4 \times 10^{4}\right.$ cells/well) in a 24-well plate were transfected with either the control plasmid without PARP-1 3'UTR (pmiRTarget) or plasmid harboring the full length PARP-1 3'UTR (pmiRTargetUTR), or the pPARP3'UTRMut using Lipofectamine 3000 (Invitrogen) and incubated for $48 \mathrm{~h}$. The transfection efficiency was measured by red fluorescence protein (RFP) expression. Transfected cells after treatment were lysed using $1 \times$ passive lysis buffer (Promega) and luciferase activity in the cell extracts was measured using a plate reader (BioTek). Samples were assayed in triplicate and the data are shown as luciferase activity normalized to RFP expression.

\section{Animals}

All protocols were approved by the Institutional Animal Care and Use Committee at Icahn School of Medicine at Mount Sinai. For all experiments, 9- to 11-week-old C57BL/6J male mice (The Jackson Laboratory) were group housed (five per cage) in a colony room set at a constant temperature $\left(23^{\circ} \mathrm{C}\right)$ on a $12 / 12 \mathrm{~h}$ light/dark cycle (lights on from 7 A.M. to 7 P.M.) with ad libitum access to food and water. For acute cocaine treatment the mice were injected (i.p.) with cocaine at $20 \mathrm{mg} / \mathrm{kg}$ body weight for $1 \mathrm{~h}$ while for chronic cocaine treatment the animals received daily i.p. injections for seven consecutive days of cocaine at $20 \mathrm{mg} / \mathrm{kg}$ unless otherwise stated. For time course experiments, animals were given daily injections (i.p.) of cocaine $(20 \mathrm{mg} / \mathrm{kg})$ and sacrificed on day 2,4 , or 6. Control mice for all groups received saline injections. Bilateral 14-gauge NAc punches were taken from each animal and frozen immediately.

\section{Isolation of total RNA, protein, and immunoprecipitation}

Total RNA, including miRNA and protein were extracted from NAc, PFC or VTA punches using All-in-One kit (Norgen Biotek) as per the manufacturer's instructions. The isolated total RNA was used to perform miRNA and PARP-1 mRNA expression analyses as described before. The extracted proteins were used for immunoprecipitation. Equal amount of protein extracts were mixed with 1 $\mu \mathrm{l}$ of anti-PARP-1 (46D11) monoclonal antibody (Cell Signaling) in 200 \&micro; of IP buffer (50 mM HEPES, pH 7.5, $150 \mathrm{mM} \mathrm{NaCl}, 1.5 \mathrm{mM} \mathrm{MgCl}$, 1 mM EDTA, $2.5 \mathrm{mM}$ EGTA, $0.1 \%$ Tween $20,10 \%$ glycerol, and $1 \mathrm{mM}$ DTT) containing protease inhibitors. The mixture was incubated with rotation at $4^{\circ} \mathrm{C}$ overnight. After which protein G-agarose suspension was added and further incubated with rotation at $4^{\circ} \mathrm{C}$ overnight. The beads were washed four times with IP buffer. Finally, the beads were resuspended in SDS sample buffer, heated at $95^{\circ} \mathrm{C}$ for $10 \mathrm{~min}$, and briefly centrifuged. The proteins were separated by electrophoresis and detected by Western blotting.

\section{Statistical analysis}

Data were expressed as mean \pm SD obtained from three independent experiments. Significance of differences between control and treated samples was determined by Student's $t$ test. Values of $p<0.05$ were considered statistically significant.

\section{Results}

\section{Cocaine downregulates miR-125b expression in dopaminergic neuronal cell models and in the mouse NAc}

Earlier work in our laboratory showed that cocaine treatment resulted in the downregulation of miR-125b expression in lymphocytes (Mantri et al., 2012). Since miR-125b plays crucial roles in neuronal function (Le et al., 2009a and 2009b), we investigated the effects of cocaine exposure on miR-125b expression in neuronal cells. In initial studies, we used differentiated SH-SY5Y neuroblastoma cells (Fig. $1 A$ ) that express markers of 
A

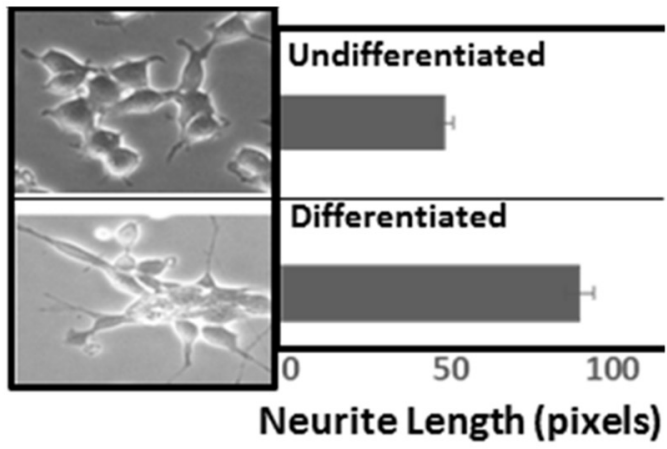

B

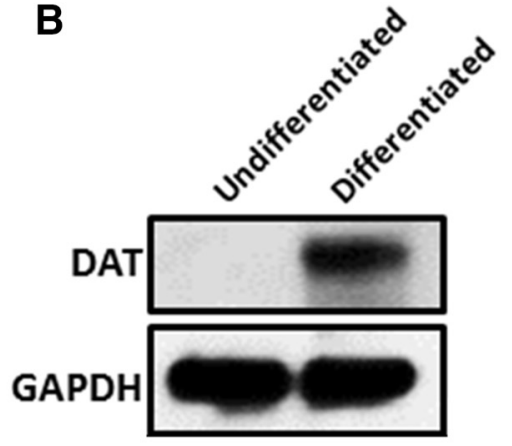

Overlay

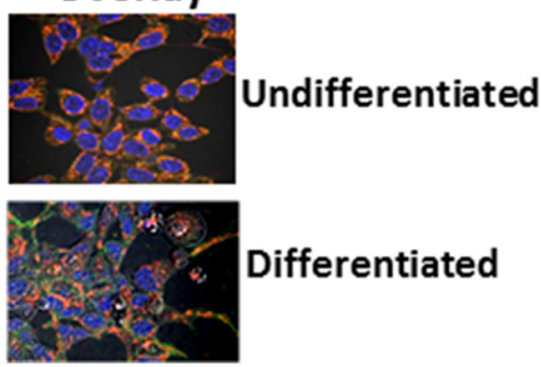

$\mathbf{E}$
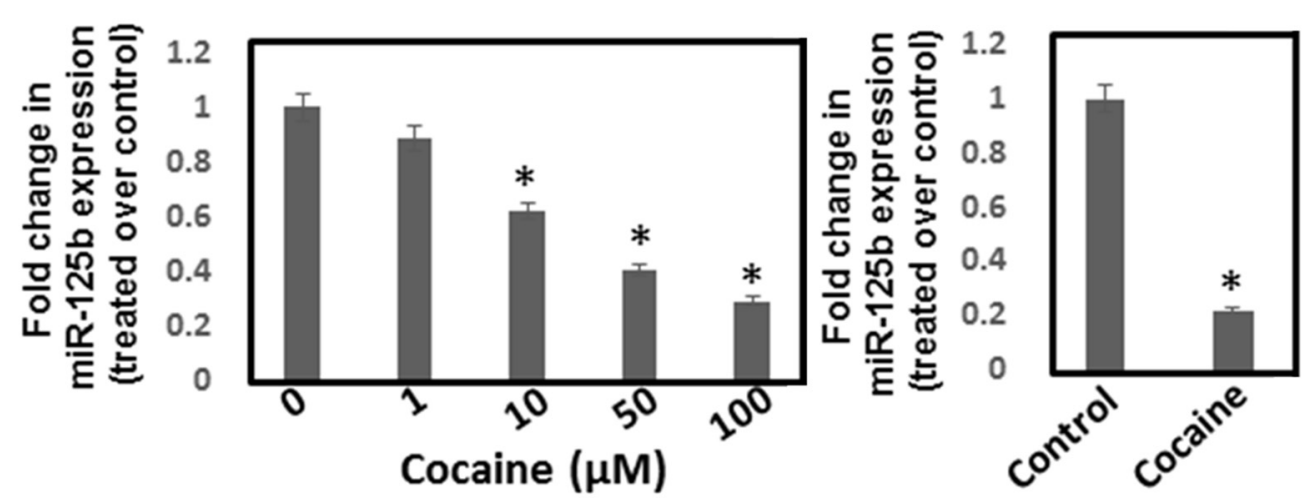

Figure 1. Cocaine exposure downregulates miR-125b expression. SH-SY5Y cells were cultured overnight and then differentiated for 3-5 d. $\boldsymbol{A}$, Dopaminergic phenotype of these cells was monitored via neurite length measurement by phase-contrast microscopy. $\boldsymbol{B}$, Western blot analysis of DAT expression in differentiated SH-SY5Y cells. C, DAT and TH expression in differentiated SH-SY5Y cells were detected by confocal microscope. Data are representative of three independent experiments. $\boldsymbol{D}$, Differentiated SH-SY5Y cells were treated with varying concentrations of cocaine. Cells were harvested and miRNA expression was analyzed by qPCR. miR-125b expression was normalized to the $5 \mathrm{~S}$ rRNA levels. Relative expression of miR-125b in cocaine-treated cells was compared to the untreated control cells and are plotted as fold change. $\boldsymbol{E}$, Mice were injected (i.p.) with a single dose of cocaine (20 mg/kg weight of mice) or saline and animals were sacrificed. NAc tissues were used for miRNA isolations and were subjected to qPCR. miR-125b expression was normalized to the 5s rRNA levels and relative expression of miR-125b in the NAc of cocaine-treated mice $(n=6)$ are expressed as fold changes to the NAc of saline-treated mice $(n=6)$. $* p<0.05$ for the comparison of cocaine-treated samples versus untreated controls.

dopaminergic neurons (Hartfield et al., 2014) such as DAT and TH (Fig. 1B,C). These cells were treated with varying concentrations of cocaine and miR-125b expression in these cells was measured by qPCR. Cocaine exposure resulted in the reduction of miR-125b expression in a dose-dependent manner relative to the untreated cells (Fig. 1D). Cells treated with 1 \&micro;M cocaine showed a minimal reduction in miR-125b expression, whereas with 100 \&micro;M cocaine, miR-125b level was reduced significantly when compared to the untreated cells (Fig. 1D).
Next, we examined the effects of cocaine exposure on miR-125b expression in a rodent model. Cocaine $(20$ $\mathrm{mg} / \mathrm{kg}$, i.p.) was administered to mice under acute conditions and the NAc, a key reward region of the brain, was isolated to measure miR-125b expression. qPCR analysis showed a significant reduction in miR-125b expression $(\sim 80 \%)$ in the NAc of animals exposed to cocaine relative to the saline control animals (Fig. 1E). Collectively, the results in Figure 1 show that acute cocaine exposure downregulates miR-125b expression in a dopaminergic neuronal cell model and in the NAc of mice. 
A
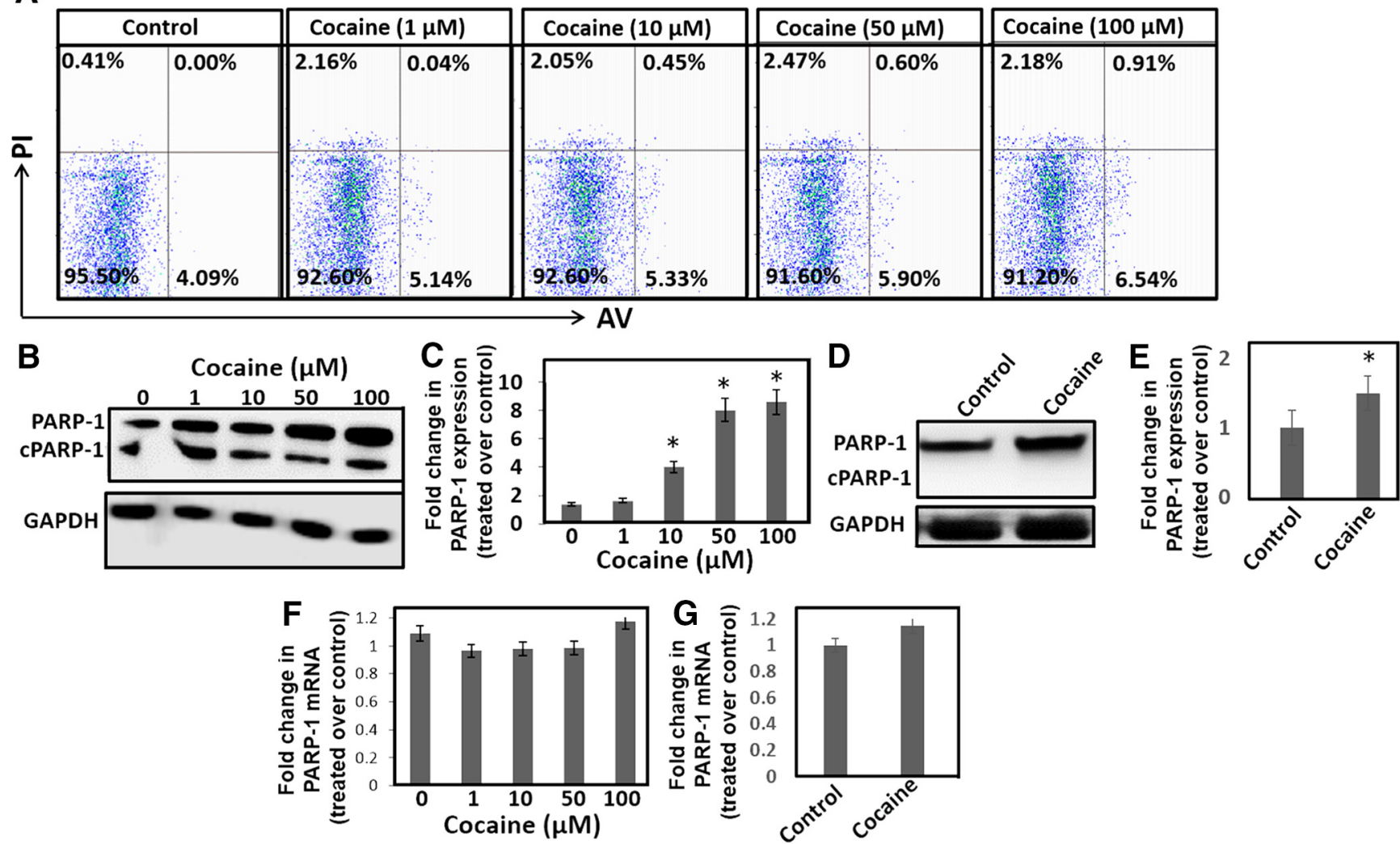

Figure 2. Cocaine exposure induces PARP-1 protein expression without increasing mRNA levels. $\boldsymbol{A}$, Differentiated SH-SY5Y cells were exposed to different concentrations of cocaine overnight and apoptosis was measured by flow cytometry using AV- as an early apoptosis marker and PI- as the late apoptotic marker. After cocaine treatment, cells were harvested and stained with FITCconjugated AV/PI and analyzed by flow cytometry. Representative dot blot data showing percentage of cells stained positive for AV, $\mathrm{PI}$, and AV + PI. B, Differentiated SH-SY5Y cells were treated with varying concentrations of cocaine. Cells were harvested, and cell lysates were electrophoresed on denaturing acrylamide gels and transferred onto nitrocellulose membrane by electroblotting. Western blot analyses were performed using appropriate antibody and ECL kit. Representative data of PARP-1 expression in untreated and cocaine-treated cells. $\boldsymbol{C}$, Densitometry of PARP-1 expression from three independent experiments. $\boldsymbol{D}$, Mice were injected (i.p.) with a single dose of cocaine $(20 \mathrm{mg} / \mathrm{kg}$ weight of mice, i.p.) or saline. Animals were sacrificed and NAc was isolated. Lysates prepared from the NAc tissues were subjected to western blot analysis. (E) Relative expression of PARP-1 in the NAc of cocaine-treated mice $(n=6)$ compared to the NAc of saline-treated mice $(n=6)$. *p $<0.05$ for the comparison of cocaine-treated samples versus untreated controls. (F) Differentiated SH-SY5Y cells were treated with varying concentrations of cocaine overnight. Cells were harvested and total RNA was isolated. PARP-1 mRNA expression was measured by qPCR and was normalized to the levels of GAPDH mRNA. PARP-1 mRNA in cocaine-treated cells were expressed as fold changes over the untreated control cells based on $\Delta \Delta$ Ct values. G, Mice were injected (i.p.) with a single dose of cocaine $(20 \mathrm{mg} / \mathrm{kg}$ weight of mice) or saline. Animals were sacrificed and NAc was isolated. Total RNA was isolated from the NAc tissues and were subjected to qPCR. PARP-1 mRNA expression was normalized to the GAPDH mRNA levels and fold changes in PARP- 1 mRNA in the NAc of cocaine-treated mice $(n=$ $6)$ over the NAc of saline-treated mice $(n=6)$ were calculated based on $\Delta \Delta \mathrm{Ct}$ values.

\section{Cocaine induces PARP-1 expression without eliciting neuronal apoptosis}

miR-125b negatively regulates p53 and a network of p53-induced genes that play critical roles in cellular apoptosis (Le et al., 2009a and 2009b). Therefore, we tested whether downregulation of miR-125b on cocaine treatment resulted in neuronal apoptosis. Differentiated $\mathrm{SH}-$ SY5Y cells were treated with increasing concentrations of cocaine and apoptosis was measured by flow cytometry using AV and PI staining. Surprisingly, cells treated with cocaine showed minimal increase in $\mathrm{AV}$ or PI staining compared to the untreated cells (Fig. 2A). Even in cells treated with the highest concentration of cocaine (100 \&micro;M), AV and PI staining remained relatively un- changed indicating minimal induction of neuronal apoptosis. We also measured expression of apoptotic markers such as caspase-9 and PARP-1 in cells treated with cocaine. Western blot analysis of the cellular lysates showed that cocaine treatment has no/minimal effect on the expression of caspase- 9 or its cleaved forms (data not shown). Similarly, levels of cleaved PARP-1 remained unchanged in cells treated with or without cocaine (Fig. $2 B$ ), supporting the data in Figure $2 A$ that cocaine exposure has minimal impact on neuronal apoptosis. Unpredictably, cocaine treatment resulted in a significant induction of total PARP-1 expression in these cells (Fig. $2 B$ ). Densitometry analysis showed a $\sim$ eight to nine fold increase in total PARP-1 expression in cells treated with 
$100 \mu \mathrm{M}$ cocaine compared to the untreated cells (Fig. 2C). Accordingly, induction of PARP-1 in the NAc of mice has been reported during chronic cocaine administration (Scobie et al., 2014). Therefore, we examined whether acute exposure of cocaine induced PARP-1 expression in the NAc of mice. Western blot analysis showed that PARP-1 expression was significantly induced in the NAc of mice treated with cocaine compared to the control animals (Fig. 2D,E). In addition, the levels of cleaved PARP-1 in the NAc was undetectable both in cocainetreated and -untreated animals. The level of increased PARP-1 in NAc was consistent with the report by Scobie et al. (2014), albeit to a lower degree when compared to the neuronal cells. Nevertheless, results in Figure 2 suggest that cocaine-induced downregulation of miR-125b is not associated with neuronal apoptosis and induction of PARP-1 play important roles in the cellular and molecular effects of cocaine that is distinct from its reported role in cellular apoptosis.

\section{Cocaine induces PARP-1 expression through a post-transcriptional mechanism}

PARP-1 expression is regulated transcriptionally by transcription factors $\mathrm{Sp} 1, \mathrm{YY}-1$, and $\mathrm{NF}-\kappa \mathrm{B}$ (Oei et al., 1997; Hassa and Hottiger, 1999; Zaniolo et al., 2007; Doetsch et al., 2012). Thus, to test whether PARP-1induction by cocaine is transcriptionally regulated, we quantified PARP-1 mRNA levels. Total mRNA from differentiated SH-SY5Y cells and the NAc tissues were subjected to qPCR. Interestingly, qPCR data revealed that PARP-1 mRNA levels were not significantly altered on cocaine treatment (Fig. 2F), although total PARP-1 protein levels were significantly increased in cocaine-treated cells (Fig. 2B). Similarly, minimal effect in the PARP-1 mRNA expression was observed in the NAc of cocaine-treated mice when compared to the saline-treated animals (Fig. $2 G)$. These data suggest that cocaine-induced PARP-1 expression is not dependent on increased transcription and are consistent with the observation that transcriptional regulation does not sufficiently account for the increased PARP-1 expression by chronic cocaine exposure (Scobie et al., 2014).

\section{PARP-1 expression is post-transcriptionally regulated by $\mathrm{miR}-125 \mathrm{~b}$}

Based on the data in Figure 2F,G, we envisioned that cocaine treatment induces PARP-1 expression via posttranscriptional mechanism. Although involvement of such mechanism in neuronal cells or by cocaine has not been previously reported, post-transcriptional regulation of PARP-1 has been documented in cancer cells (Schiewer and Knudsen, 2014). Interestingly, our data showed that cocaine exposure downregulated miR-125b levels (Fig. 1), concurrent with upregulation of PARP-1 expression (Fig. 2). Since miRNAs negatively regulate protein expression by binding to the 3'UTR of target mRNA (Bartel, 2009), we hypothesized that PARP-1 expression is posttranscriptionally regulated by $\mathrm{miR}-125 \mathrm{~b}$. In initial studies, we employed in silico analysis (Rehmsmeier et al., 2004) and identified three putative miR-125b binding sites at the 5'-end of the 3'UTR of PARP-1 mRNA (data not shown).
Secondary structural analysis suggest that the site spanning the nucleotides 326-348 position of PARP-1 3'UTR is optimal for miR-125b binding (Fig. 3A). Importantly, this putative binding site, but not the other two, is evolutionarily conserved in the PARP-1 3'UTRs of several mammalian species (Fig. 3B). Thus, we tested a functional role of miR-125b in PARP-1 expression, by conducting knockdown and overexpression studies using anti-miR and miR-mimic oligonucleotides. Anti-miR-125b or miR-125b mimics were transfected into differentiated SH-SY5Y cells and expression of PARP-1 protein was measured in the cellular lysates by immunoblot. Results from these analyses showed that reducing miR-125b levels increased PARP-1 expression relative to that of the scrambled controls (Fig. 3C). Conversely, increasing miR-125b levels by miR-125b mimics markedly reduced PARP-1 protein levels (Fig. 3D). These data strongly suggested that miR$125 \mathrm{~b}$ may serve as a negative regulator of PARP-1 expression in neuronal cells.

\section{MiR-125b binds to PARP-1 3'UTR to negatively regulate PARP-1 protein expression}

MiRNAs regulate protein translation by primarily binding to the 3'UTR of the target mRNA (Bartel, 2004; Jonas and Izaurralde, 2015; Lin and Gregory, 2015). Therefore, we examined whether miR-125b binds PARP-1 3'UTR through luciferase reporter assay. We used a vector containing the PARP-1 3'UTR downstream of the luciferase stop codon. The PARP-1 3'UTR construct (pPARP3'UTR) or the control plasmid (pPARP-Null) was cotransfected into HEK-293T cells with or without miR-125b mimic or anti-miR-125b. Measurement of luciferase activity in the lysates of these cells showed that enhanced miR-125b expression significantly decreased luciferase activity relative to the control cells (Fig. $4 A$ ). Conversely, reducing miR-125b levels by transfection of anti-miR$125 \mathrm{~b}$ resulted in a significant increase in luciferase activity (Fig. 4B). Since HEK-293T cells do not express endogenous DAT and lack the differentiated neuronal properties, we tested the effects of miR-125b expression on PARP-1 3'UTR activity in differentiated SH-SY5Y cells. Overexpression of miR-125b resulted in a significant reduction in luciferase activity (Fig. 4C), whereas knockdown studies of miR-125b enhanced luciferase activity (Fig. 4D). These data indicated a negative correlation between miR-125b expression and PARP-1 3'UTR driven luciferase activity.

To probe direct binding of miR-125b to PARP-1 3'UTR, we mutated specific nucleotides in the PARP-1 3'UTR sequence that are predicted to bind miR-125b (Fig. 4E). Then, we cotransfected pPARP-3'UTR or the control plasmid (pPARP-Null) in the presence of miR-125b mimic or miR-125b mutant into HEK-293T cells. As expected, luciferase activity measurements showed that overexpression of miR-125b reduced luciferase activity relative to the control cells (Fig. 4E). However, enhanced expression of miR-125b in cells cotransfected with the PARP-1 3'UTR mutant did not lead to reduction in luciferase activity (Fig. 4E). These data indicated that miR-125b negatively regulates PARP- 1 by directly binding to the 3'UTR 


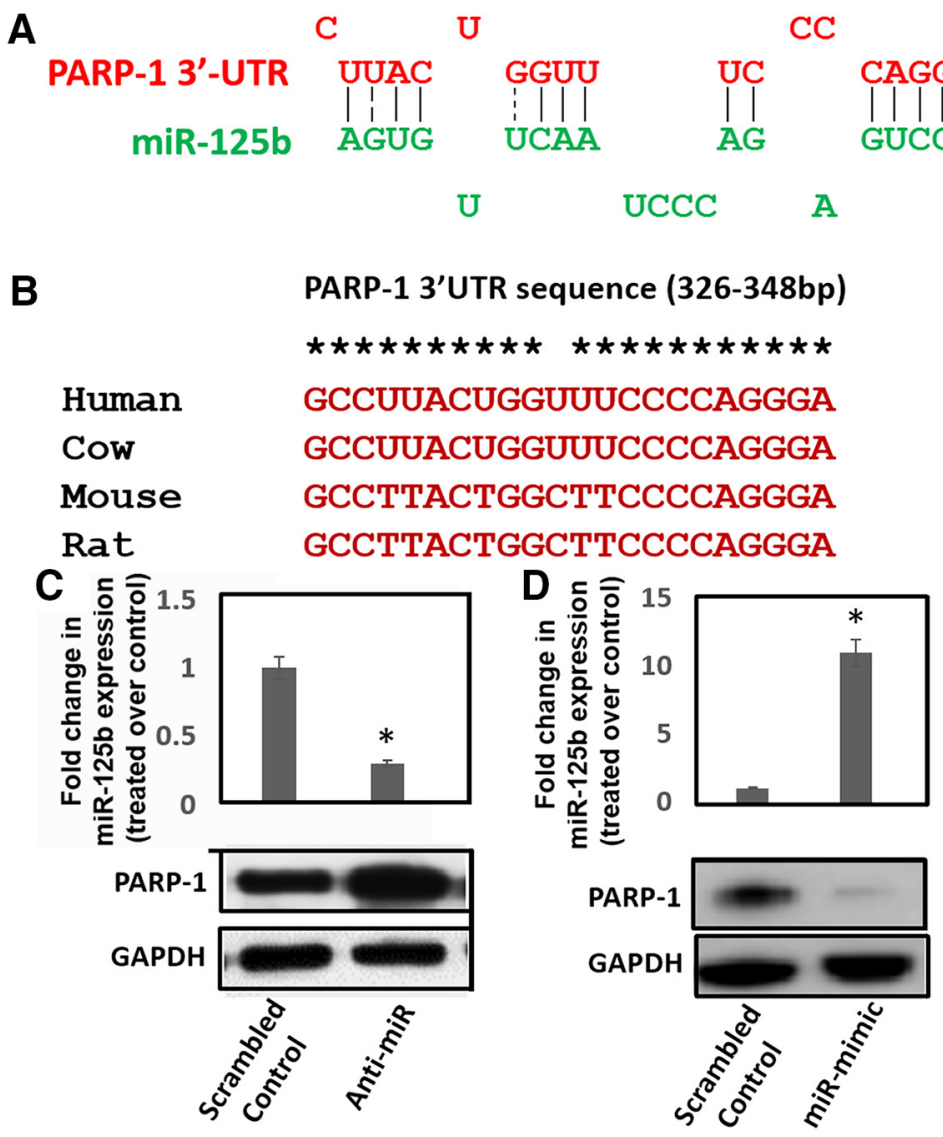

Figure 3. miR-125b expression negatively correlates with PARP-1 protein levels. $\boldsymbol{A}$, In silico analysis predicts putative binding site of miR-125b in the 3'UTR of PARP-1 mRNA. B, Sequence alignment of miR-125b binding site in the 3'UTR of PARP-1 mRNA among different mammalian species. C, upper panel, miR-125b knockdown. Chemically synthesized anti-miR-125b oligonucleotides were transfected into differentiated SH-SY5Y cells and reduction of miR-125b expression was measured $24 \mathrm{~h}$ post-transfection by qPCR. $\boldsymbol{C}$, lower panel, PARP-1 expression in miR-125b knocked-down cells was measured in the cellular lysates by immunoblot. $\boldsymbol{D}$, upper panel, miR-125b overexpression. Chemically synthesized miR-125b mimic oligonucleotides were transfected into differentiated SH-SY5Y cells and miR-125b expression was measured $24 \mathrm{~h}$ post-transfection by qPCR. $\boldsymbol{D}$, lower panel, PARP-1 expression in miR-125b overexpressing cells was measured in the cellular lysates by immunoblot. Data in $\boldsymbol{C}, \boldsymbol{D}$ are representative of three independent experiments. $* p<0.05$ for the comparison of anti-miR-125b or miR-125b mimic samples versus scrambled controls.

and support the hypothesis that PARP-1 is posttranscriptionally regulated by miR-125b in neuronal cells.

\section{Cocaine-induced downregulation of miR-125b is dependent on DAT}

DAT is well established to play critical roles in the cellular and molecular effects of cocaine addiction and reward (Kuhar et al., 1991). Thus, we examined whether binding of cocaine to DAT is key for the downregulation of miR-125b by using DAT-expressing and DAT-null HEK293T cells (Fig. 5A). These cells serve as appropriate models since they endogenously express miR-125b (Fig. $5 B, C)$. Exposure of DAT-expressing cells to increasing concentrations of cocaine resulted in a dose-dependent reduction in miR-125b levels (Fig. $5 B$ ), mirroring the observations with dopaminergic neuronal cells and animal studies (Fig. 1). Interestingly, in DAT-null cells, cocaine exposure did not result in the reduction of miR-125b expression even with the highest dose of cocaine (Fig. $5 C)$, suggesting that DAT plays a critical role in the downregulation of miR-125b expression. To further probe the involvement of DAT, we used "nomifensine," a DAT blocker and dopamine uptake inhibitor (Ferris et al., 2012). Nomifensine treatment alone did not alter miR-125b expression in DAT-expressing cells (Fig. $5 D$ ). Remarkably, pretreatment of DAT-expressing cells with nomifensine before cocaine treatment significantly abrogated cocaineinduced reduction in miR-125b expression (Fig. 5D). Next, we performed the nomifensine pretreatment studies in differentiated $\mathrm{SH}-\mathrm{SY} 5 Y$ cells as a model for dopaminergic neurons. Similar to the data in Figure $5 D$, nomifensine treatment did not change miR-125b expression in these cells. However, pretreatment of cells with nomifensine markedly reduced cocaine's effect on miR-125b expression (Fig. 5E). Collectively, these data provide strong evidence that miR-125b downregulation is dependent on the binding of cocaine to DAT.

\section{Binding of cocaine to DAT regulates miR-125b/PARP-1 axis}

Our studies with the dopaminergic neuronal cells illustrated that miR-125b expression negatively regulates 

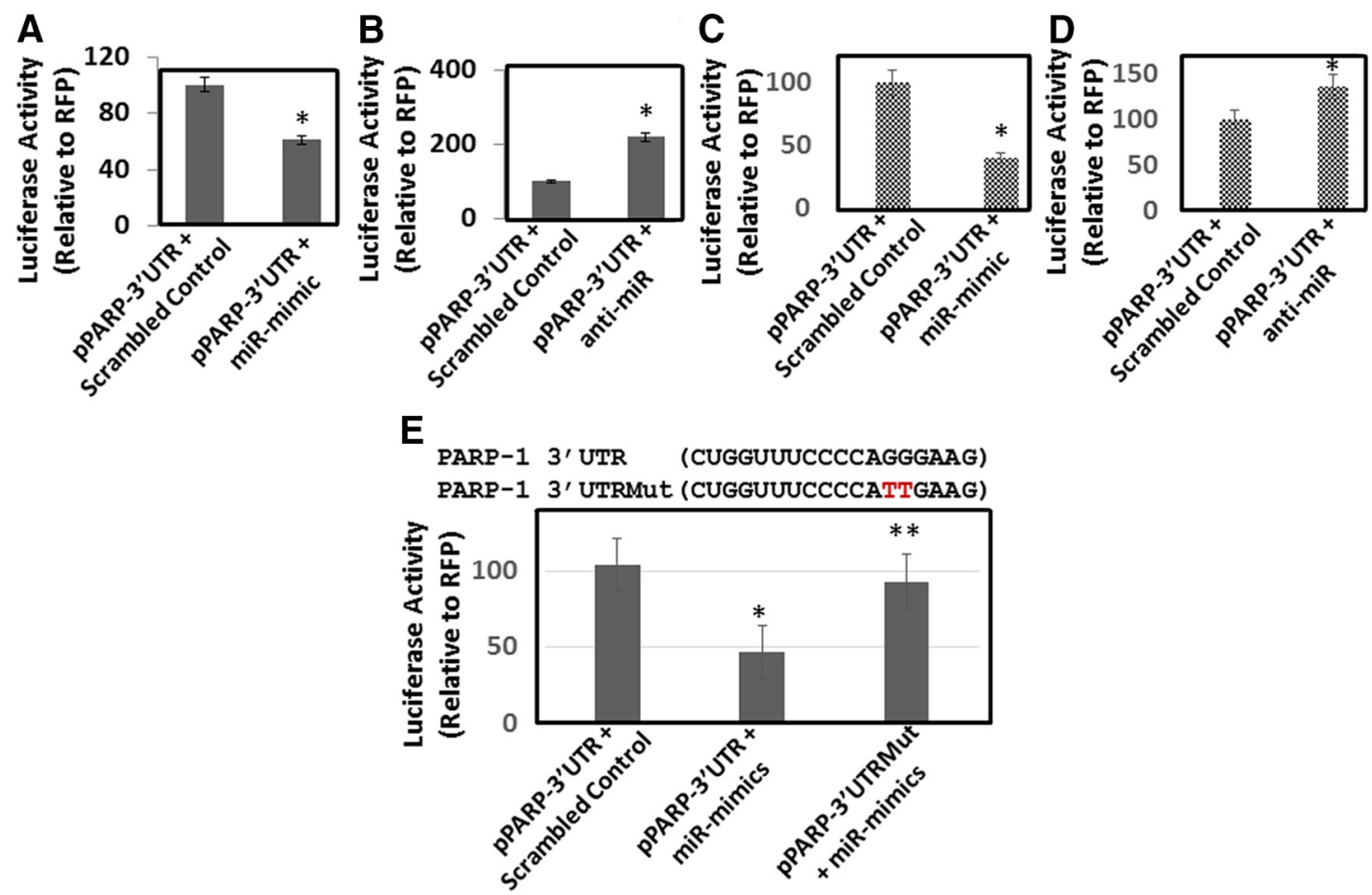

Figure 4. miR-125b targets 3'UTR of PARP-1 mRNA. We used a luciferase reporter vector, pPARP-3'UTR, containing the 3'UTR of PARP-1 mRNA cloned downstream of the luciferase stop codon. The pPARP-3'UTR was transfected into HEK-293T cells or differentiated SH-SY5Y cells in the presence or absence of miR-125b mimics or anti-miR-125b. $\boldsymbol{A}$, Luciferase activity of cellular lysates prepared from HEK-293T cells cotransfected with (pPARP-3'UTR) and scrambled control or miR-125b mimics. B, Luciferase activity in cellular lysates prepared from HEK-293T cells cotransfected with (pPARP-3'UTR) and scrambled control or anti-miR-125b. C, Luciferase activity in cellular lysates prepared from differentiated SH-SY5Y cells cotransfected with (pPARP-3'UTR) and scrambled control or miR-125b mimics. $\boldsymbol{D}$, Luciferase activity in cellular lysates prepared from differentiated SH-SY5Y cells cotransfected with (pPARP-3'UTR) and scrambled control or anti-miR-125b. E, Site-directed mutagenesis of miR-125b binding site within the PARP-1 3'UTR. Upper panel, PARP 3'UTRMut represents mutation of two critical residues GG > TT. Lower panel, Luciferase activity in cellular lysates prepared from differentiated SH-SY5Y cells transfected with pPARP 3'UTR and pPARP 3'UTRMut in the presence or absence of miR-125b mimics. $* p<0.05$ for the comparison of anti-miR-125b or miR-125b mimic samples versus scrambled controls. $\boldsymbol{E}, * * p<0.05$ for the comparison of miR-125b mimic samples of pPARP-3'UTR versus pPARP-3'UTRMut.

PARP-1 expression (Fig. 3). Data in Figure 5B,C showed that downregulation of miR-125b expression is dependent on binding of cocaine to DAT. Based on these observations, we hypothesized that cocaine exposure activates miR-125b mediated regulation of PARP-1 by binding to DAT and inhibition of DAT binding abrogates cocaine's effect on miR-125b/PARP-1 axis. To test this, we treated differentiated $\mathrm{SH}-\mathrm{SY} 5 \mathrm{Y}$ cells with cocaine and asked whether pretreatment of nomifensine affected cocaine-induced PARP-1 expression. Lysates of cells exposed to cocaine with or without nomifensine pretreatment were subjected to Western blot analysis. As expected cocaine treatment increased PARP-1 expression, whereas nomifensine treatment did not alter PARP-1 levels (Fig. 5F,G). However, cocaine-induced PARP-1 expression was abrogated in cells that were pretreated with the inhibitor (Fig. 5F,G). These data provided further evidence that cocaine-induced PARP-1 expression and the concurrent miR-125b downregulation is primarily driven by direct binding of cocaine to DAT. Finally, we tested whether overexpression of miR-125b abrogates cocaine's effect on PARP-1 expression. miR-125b mimics were transfected into differentiated SH-SY5Y cells and overexpression of miR-125b was confirmed by qPCR (data not shown). Then, these cells were treated with cocaine (50 \&micro;M) overnight and PARP-1 expression was measured by immunoblot. Results in Figure $5 \mathrm{H}$ show that cocaine treatment induced PARP-1 expression in control cells (lane 2 and lane 4). However, miR-125b overexpression inhibited induction of PARP-1 on cocaine treatment (lane 3). These observation strongly support the hypothesis that cocaine's effect on PARP-1 expression is regulation by miR-125b

\section{Chronic cocaine exposure activates miR-125b/PARP-1 axis}

Our results showed that acute cocaine exposure downregulates miR-125b leading to the upregulation of PARP-1. It has also been reported that chronic cocaine exposure upregulates PARP-1 expression in NAc of mice (Scobie et al., 2014). Therefore, we examined whether cocaine targets miR-125b under chronic exposure conditions both in vitro and in vivo. Differentiated SH-SY5Y cells were exposed to cocaine $(50 \mu \mathrm{M})$ for $7 \mathrm{~d}$. To reduce degradation of cocaine in the culture media, we used heat-inactivated serum in the media. QPCR analysis showed that chronic cocaine exposure resulted in a dose- 

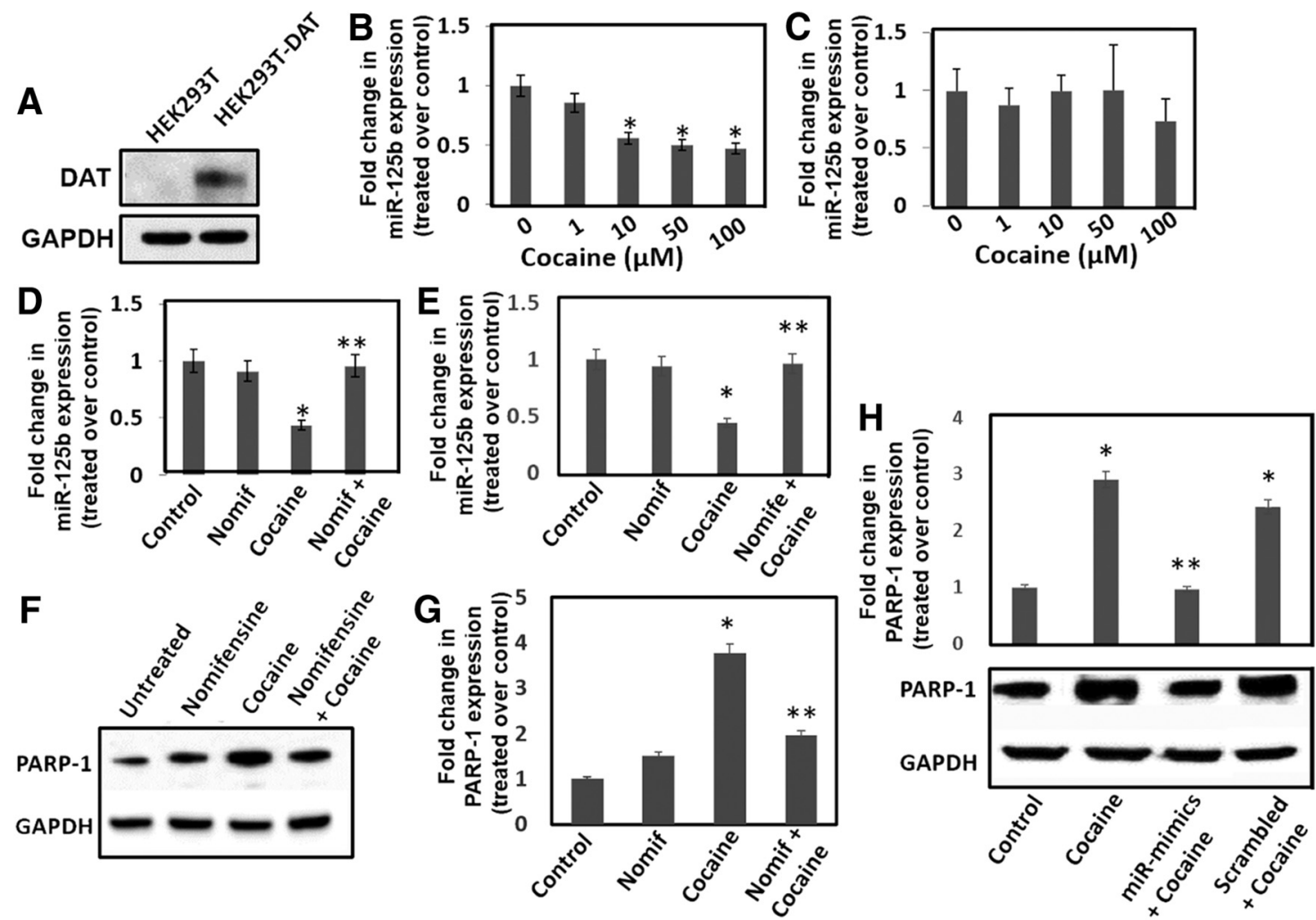

Figure 5. Cocaine-induced downregulation of miR-125b and concurrent upregulation of PARP-1 is dependent on DAT. $\boldsymbol{A}$, Detection of DAT in the HEK-293T-DATNull and HEK-293T-DAT cells by immunoblot. Fold change in miR-125b expression in (B) HEK-293TDAT cells and $(\boldsymbol{C})$ HEK-293T-DAT-Null cells on exposure to varying concentration of cocaine relative to untreated cells as measured by qPCR. $\boldsymbol{D}$, Fold change in miR-125b expression in HEK-293T-DAT cells pretreated with nomifensine. $\boldsymbol{E}$, $\boldsymbol{G}$, Differentiated SH-SY5Y cells with or without nomifensine pretreatment were treated with cocaine. $\boldsymbol{E}$, miR-125b expression was measured in these cells by qPCR. $\boldsymbol{F}$, PARP-1 expression was measured in the cell lysates by Western blotting. $\boldsymbol{G}$, Densitometry of PARP-1 expression from three independent experiments. $\boldsymbol{H}$, Differentiated SH-SY5Y cells were transfected with miR-125b mimics or scrambled controls and then treated with cocaine $(50 \mu \mathrm{M})$ overnight. PARP-1 expression was measured in the lysates of these cells by immunoblot. Lower panel shows representative data, whereas upper panel shows fold change in PARP-1 expression from three independent experiments. $* p<0.05$ for the comparison of cocaine-treated samples versus untreated controls. $\boldsymbol{D}, \boldsymbol{E}, \boldsymbol{G}, * * p<0.05$ for the comparison of cocaine-treated samples versus nomifensine + cocaine-treated samples. $\boldsymbol{H}, * * p<0.05$ for the comparison of cocaine-treated samples versus miR-mimic + cocaine-treated samples.

dependent reduction in miR-125b expression (Fig. 6A). In addition, Western blot analysis illustrated increased PARP-1 levels in cocaine exposed neuronal cells without significant change in the cleaved form (Fig. 6B,C). Similarly, cocaine was administered to mice under chronic conditions ( $7 \mathrm{~d}$ with one dose daily) and NAc regions of mice either treated with cocaine or saline were isolated. Total RNA and protein were isolated from NAc for analyses of miR-125b and PARP-1 expression, respectively. We observed that, similar to the acute cocaine treatment, chronic cocaine exposure significantly downregulated miR-125b expression in NAc compared to saline-treated mice (Fig. 6D). Moreover, we also observed increased PARP-1 protein levels in the NAc of mice exposed to chronic cocaine treatment albeit accompanied by a slight increase in cleaved PARP-1 level (Fig. 6E,F).

To better understand the effects of cocaine exposure on miR-125b and PARP-1 expression, we conducted time course analysis of miR-125b downregulation and PARP-1 induction on cocaine treatment. Animals were given daily injections of cocaine $(20 \mathrm{mg} / \mathrm{kg})$ and sacrificed on day 2 ,
4, and 6. NAc was isolated and analyzed for miR-125b and PARP-1 expression. GPCR data showed that miR$125 \mathrm{~b}$ expression remained downregulated throughout the $6 \mathrm{~d}$ of cocaine administration (Fig. $7 A-C$ ). Immunoblot analysis revealed that PARP-1 expression was consistently upregulated during treatment period (Fig. 7D-F). Taken together, these results illustrate that cocaineinduced downregulation of miR-125b is associated with increased levels of PARP-1 expression both under acute and chronic conditions.

\section{Effects of cocaine exposure on miR-125b and PARP-1 in the VTA and PFC}

To examine whether cocaine regulates $\mathrm{miR}-125 \mathrm{~b}$ and PARP-1 expression specifically in the NAc, we tested the effects of cocaine in other regions of the brain's reward pathway including VTA and PFC. Cocaine $(20 \mathrm{mg} / \mathrm{kg})$ was administered to mice under acute and chronic conditions and the VTA and PFC were isolated. RNA and protein preparations of these tissues were subjected to qPCR and immunoblot analysis to measure miR-125b and 

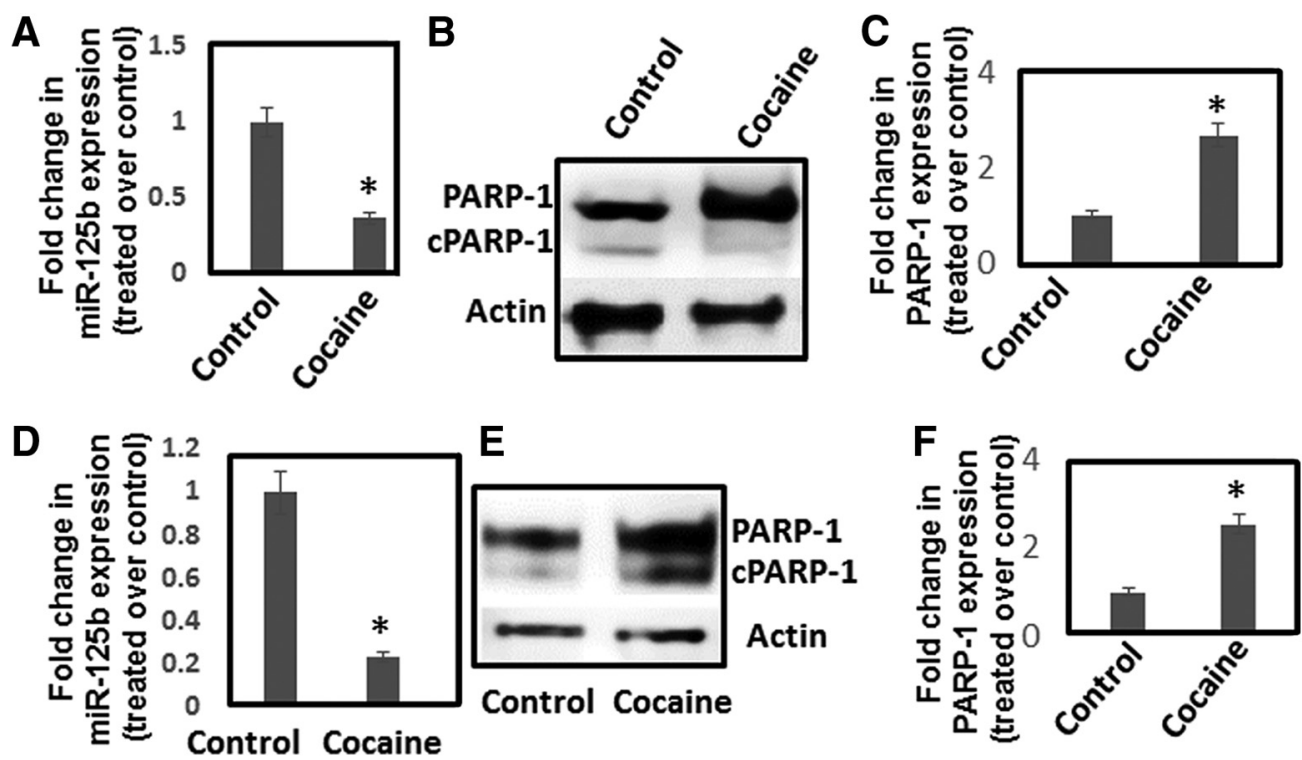

Figure 6. Chronic cocaine exposure reduces miR-125b expression and upregulates PARP-1 expression. A-C, Differentiated SH-SY5Y cells were treated daily with varying concentrations of cocaine for $7 \mathrm{~d}$. Cells were harvested, and miR-125b expression was measured by qPCR $(\boldsymbol{A})$, whereas PARP-1 expression was detected by Western blotting (B, C). $\boldsymbol{A}$, miR-125b expression was normalized to 5S rRNA levels and plotted as fold changes in miR-125b expression in cocaine-treated cells relative to untreated control. $\boldsymbol{B}$, Representative immunoblot of PARP-1 expression in control and cocaine-treated cells. $\boldsymbol{C}$, Relative PARP-1 expression in cocaine-treated cells and untreated cells as quantified by densitometry from three independent experiments. $\boldsymbol{D}$ - $\boldsymbol{F}$, Mice were injected (i.p.) with cocaine $(20 \mathrm{mg} / \mathrm{kg}$ weight of mice) or saline for $7 \mathrm{~d}$. Thereafter, animals were sacrificed and NAc was isolated. RNA and lysates from the NAc tissues were subjected to qPCR and Western blotting, respectively. $\boldsymbol{D}$, miR-125b expression was normalized to the $5 s$ rRNA levels and relative expression of miR-125b in the NAc of cocaine-treated mice $(n=6)$ compared to the NAc of saline-treated mice $(n=6)$ are expressed as fold changes. $\boldsymbol{E}$, Representative immunoblot showingPARP-1 expression in the NAc of cocaine-treated mice and saline-treated control mice. $\boldsymbol{F}$, Relative expression of PARP-1 in the NAc of cocaine-treated mice $(n=6)$ compared to the NAc of saline-treated control mice $(n=6)$ based on densitometry analysis. $* p<0.05$ for the comparison of cocaine-treated samples versus untreated controls.

PARP-1 expression, respectively. Data from these analysis revealed that both acute and chronic cocaine treatment minimally affected miR-125b expression (Fig. 8A) and PARP-1 expression (Fig. 8B,C) in PFC. However, in the VTA, while PARP-1 expression was not affected (Fig. $8 E, F)$, miR-125b levels were significantly elevated by acute and chronic cocaine treatment (Fig. 8D). These results suggest that miR-125b levels is not negatively correlated with PARP-1 expression in the VTA. Still, these results show that a marked effect on the downregulation of miR-125b and PARP-1 induction is largely restricted to the NAc after acute and chronic cocaine exposure.

\section{Discussion}

Cocaine-induced alterations in cellular miRNA expression and subsequent post-transcriptional regulation of gene expression in specific brain regions are well documented (Hollander et al., 2010; Chen et al., 2013; Xu et al., 2013; Doura and Unterwald, 2016). In the mesolimbic dopaminergic system, chronic cocaine administration downregulates expression of let-7d and miR-124 while upregulating miR-181a (Chandrasekar and Dreyer, 2009; Chandrasekar and Dreyer, 2011), Accordingly, in the dorsal striatum, cocaine exposure upregulates miR-212 along with its homolog miR-132 (Im et al., 2010). In the hippocampus, cocaine upregulates miR-181a (Chandrasekar and Dreyer, 2009) and several other miRNAs, including miR-134, miR-152, and miR-26b (Chen et al.,
2013). A set of miRNAs were also shown to be specifically modulated in the striatal post-synaptic densities (PSDs; Eipper-Mains et al., 2011). Altered expression of these cellular miRNAs has been demonstrated to play functional roles in cocaine reward and addiction. Results described in this report provide evidence that miR-125b is important for cocaine's action in the brain.

MiR-125b is highly expressed in the mammalian brain and regulates several key functions including neuron survival, differentiation, and synaptic plasticity (LagosQuintana et al., 2002; Le et al., 2009). Previous work from our laboratory has demonstrated that cocaine downregulates miR-125b expression in human CD4 + T cells (Mantri et al., 2012). In this study, we report that both acute and chronic cocaine exposure downregulates miR-125b expression in an in vitro model of dopaminergic neuronal cells and in vivo in the NAc region of mice (Fig. 1). Although downregulation of miR-125b is well established to activate cellular apoptotic pathway (Le et al., 2009a and $2009 \mathrm{~b}$ ), exposure of cocaine did not induce neuronal apoptosis as measured by AV/PI staining and cleavage of PARP-1 (Fig. 2). Surprisingly, a significant increase in the total PARP-1 protein was observed in response to cocaine exposure both in vitro (Fig. 2) and in vivo (Fig. 6). These results are in accordance with the reported induction of PARP-1 protein levels in NAc on chronic cocaine administration (Scobie et al., 2014). 
A

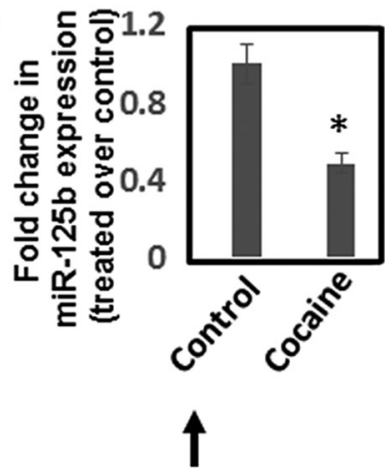

(Day 2)
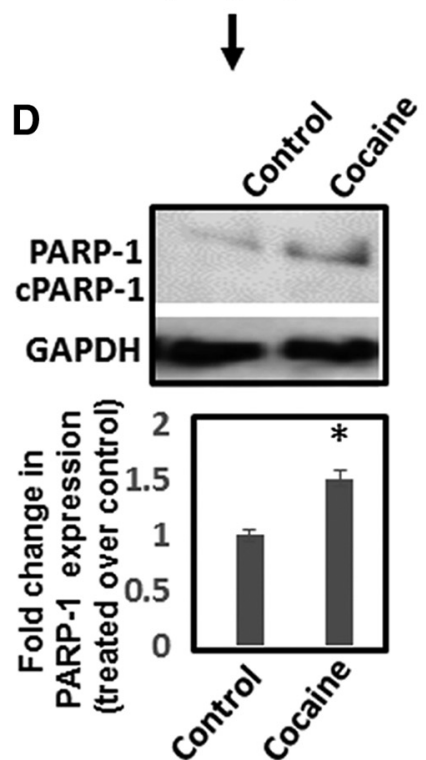

B

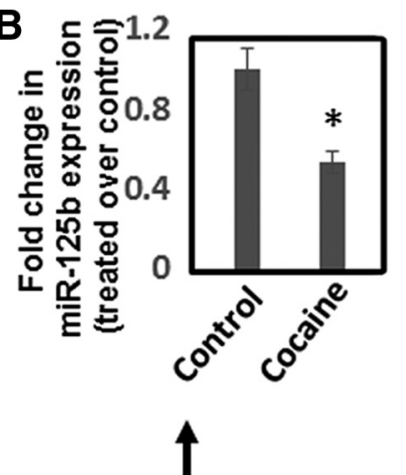

(Day 4)

$E$
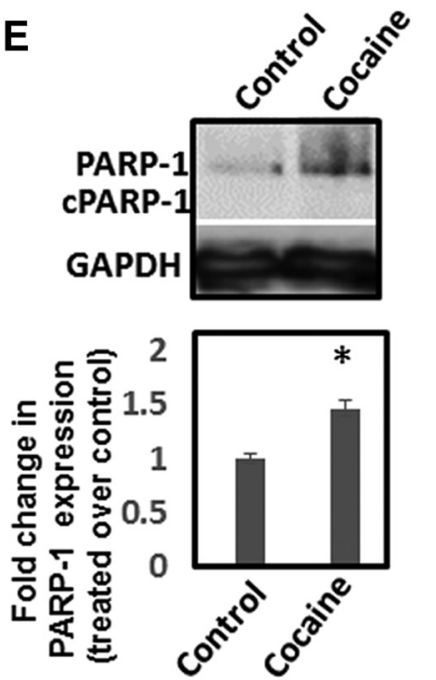

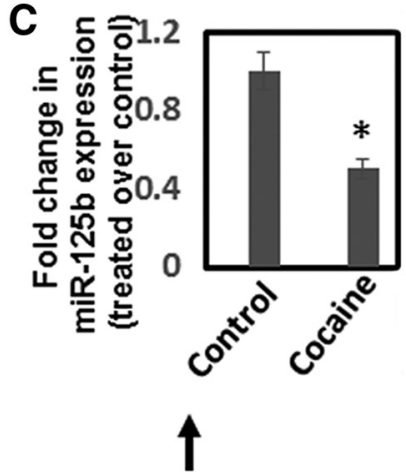

(Day 6)

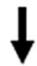

$F$
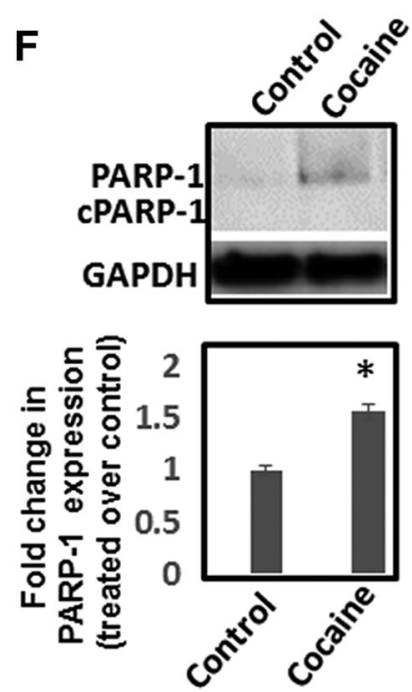

Figure 7. Time-dependent effects of cocaine exposure on miR-125b and PARP-1 expression in NAc. Mice were injected (i.p.) with cocaine (20 mg/kg weight of mice) or saline for 2, 4, and $6 \mathrm{~d}$. Thereafter, animals were sacrificed, and NAc regions were isolated. RNA and lysates from the NAc tissues were subjected to qPCR and Western blotting for measuring miR-125b and PARP-1 expression, respectively. $\boldsymbol{A}-\boldsymbol{C}$, Fold changes in miR-125b expression in cocaine-treated $(n=6)$ and saline-treated control $(n=6)$ animals on $(\boldsymbol{A})$ day $2,(\boldsymbol{B})$ day 4 , and $(\boldsymbol{C})$ day 6 . D-F, PARP-1 protein expression in the NAc tissues was analyzed by immunoblot and subjected to quantification by densitometry. Upper panels show representative data of PARP-1, whereas lower panels show densitometry of PARP-1 expression from cocaine-treated mice $(n=6)$ and saline-treated control animals $(n=6)$. Fold changes in PARP-1 expression in cocaine-treated mice and saline-treated controls as measured by densitometry of immunoblots of samples on $(\boldsymbol{D})$ day 2 , $(\boldsymbol{E})$ day 4 , and $(\boldsymbol{F})$ day 6 . *p $<0.05$ for the comparison of cocaine-treated samples versus untreated controls.

PARP-1 is a highly conserved nuclear enzyme that plays a central role in cellular stress response, DNA damage, and repair (Lupo and Trusolino, 2014; Morales et al., 2014; Schiewer and Knudsen, 2014). PARP-1 also regulates cellular gene expression (Fontan-Lozano et al., 2010; Verdone et al., 2015), since activation of PARP-1 results in the addition of negatively charged PAR (aka PARylation) to histones that induce chromatin remodeling (Krishnakumar and Kraus, 2010; Wei and Yu, 2016). Because of these essential roles, PARP-1 is also involved in neuronal function, learning and memory $(\mathrm{Ha}$ and Snyder, 2000; Cohen-Armon et al., 2004; Fontan-Lozano et al., 2010; Wang et al., 2012). For example, recent evidence suggests that PARP-1 and PARylation play crucial roles in cocaine induced molecular, neural, and behavioral plasticity (Scobie et al., 2014; Scobie, 2015). Yet, the cellular mechanisms that regulate PARP-1 expression are poorly defined. There is evidence that PARP-1 expression is transcriptionally regulated by transcriptional factors such as Sp1, YY1, AP-2, ETS, and NF-1 (Oei et al., 1997; Hassa and Hottiger, 1999; Zaniolo et al., 2007; Doetsch et al., 2012). Accordingly, in silico studies of the PARP-1 promoters of several mammalian species predicted potential binding sites of several other transcriptional factors (Oei et al., 1997; Hassa and Hottiger, 1999; Zaniolo et al., 2007; Doetsch et al., 2012). Interestingly, in cancer cells, PARP-1 expression has been reported to be posttranscriptionally regulated by miR-124 (Chen et al., 2015). Similarly, a negative correlation between miR-223 expression and PARP-1 mRNA levels was also observed (Meloche et al., 2015). However, the cellular and molecular determinants that regulate PARP-1 expression in neurons are largely unknown. 

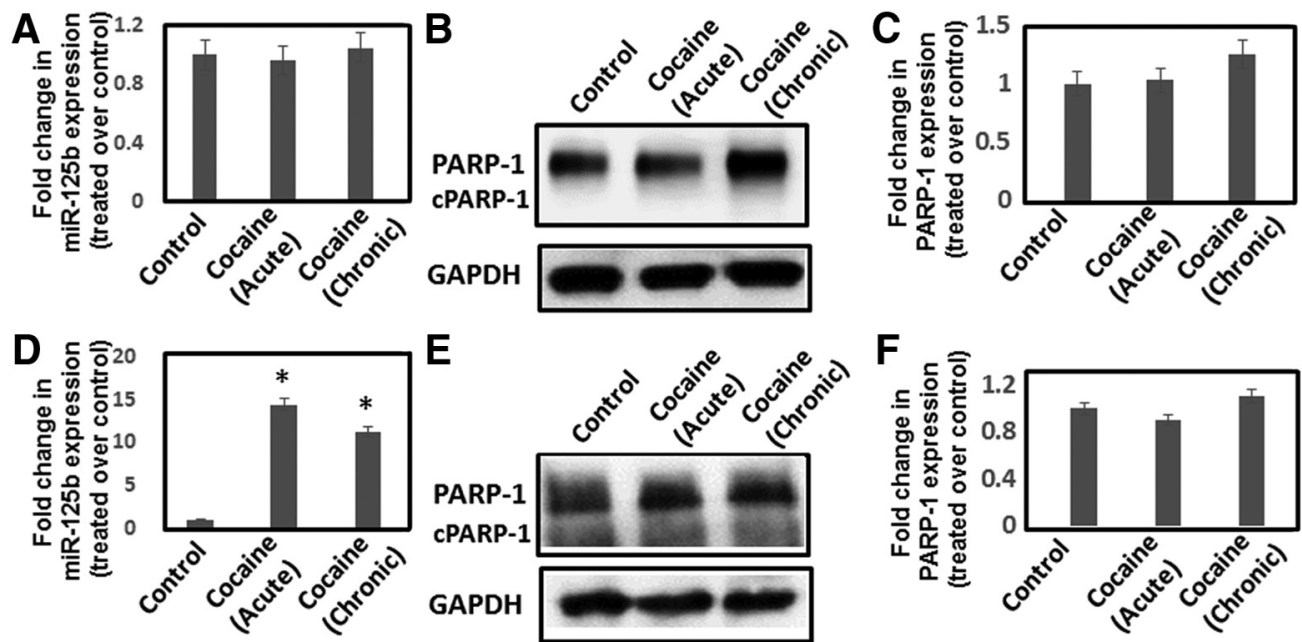

Figure 8. Effects of cocaine exposure on miR-125b and PARP-1 expression in PFC and VTA. Mice were injected (i.p.) with cocaine (20 mg/kg weight of mice) or saline under acute and chronic conditions. Thereafter, animals were sacrificed and PFC (A-C) and VTA $(\boldsymbol{D}-\boldsymbol{F})$ were isolated. RNA and lysates from the tissues were subjected to qPCR and Western blotting for measuring miR-125b and PARP-1 expression, respectively. Fold changes in miR-125b expression in (A) the PFC and (D) the VTA of cocaine-treated animals and saline-treated control animals were calculated. PARP-1 expression in (B) the PFC and (E) the VTA of cocaine-treated mice and saline-treated controls as measured by immunoblot. Fold changes in PARP-1 protein expression in $(\boldsymbol{C})$ the PFC and (F) the VTA of cocaine-treated mice $(n=6)$ compared to saline-treated control mice $(n=6)$. $* p<0.05$ for the comparison of cocaine-treated samples versus untreated controls.

We provide strong evidence that PARP-1 is posttranscriptionally regulated by $\mathrm{miR}-125 \mathrm{~b}$ in neuronal cells. We observed that PARP-1 induction is correlated with reduction in miR-125b expression both in dopaminergic neuronal cultures and NAc of mice by acute and chronic cocaine exposure (Figs. 1E,F, 6A,E). Interestingly, our qPCR analysis showed that cocaine exposure minimally increased PARP-1 mRNA levels (Fig. 2F,G), similar to the observations by Scobie et. al. that induction of PARP-1 protein expression by cocaine is not entirely dependent on increase in mRNA levels (Scobie et al., 2014). These observations led us to hypothesize that cocaine-mediated downregulation of miR-125b is the key driver of the increased PARP-1 expression through post-transcriptional mechanism(s). Initial in silico analysis predicted a binding site of miR-125b in the 3'UTR sequence of PARP-1 that is conserved in several mammalian species (Fig. $3 A, B$ ). Genetic experiments demonstrated that altering miR-125b levels either by anti-miRs or miR-mimics negatively correlated with PARP-1 protein expression in neuronal cells (Fig. $3 C, D$ ). Subsequently, luciferase reporter based analysis revealed that miR-125b targets the 3'UTR region of PARP-1 mRNA (Fig. 4A-D). Finally, specific mutations in the 3'UTR of PARP-1 confirmed that miR-125b directly binds to PARP-1 3'UTR to inhibit protein translation (Fig. $4 E$ ). These results identify miR-125b as a key post-transcriptional/translational regulator of PARP-1 expression in neuronal cells.

Differential regulation of miRNAs in brain reward regions in response to cocaine has been reported by several laboratories (Chandrasekar and Dreyer, 2009; EipperMains et al., 2011; Heyer and Kenny, 2015). Accordingly, we observed downregulation of miR-125b and induction of PARP-1 by cocaine in a region specific manner. Cocaine exposure reduced miR-125b levels and enhanced
PARP-1 expression primarily in the NAc (Figs. 1E, 2D,E) but not in the PFC (Fig. 8A-C). PARP-1 expression also remained unchanged in the VTA region in response to cocaine (Fig. 8E,F). However, increased levels of miR$125 \mathrm{~b}$ were observed in VTA on cocaine treatment (Fig. $8 D$ ). The lack of negative correlation between miR-125b expression and PARP-1 levels in the VTA suggested alternative regulatory mechanism(s) in this region of the brain. It is well recognized that regionally selective gene expression patterns drive the behavioral changes involved in drug addiction and reward (Nestler, 2004). One of the hallmark effects of cocaine-induced behavioral changes are mediated by alteration in structure and function of medium spiny neurons (MSNs) and their inputs (Lee et al., 2006; Anderson and Self, 2017). These alterations are dependent on localized de novo protein synthesis at specific synapses that modulate dendrite morphology (Schratt et al., 2006). Cocaine-responsive miRNAs have been identified that could possibly regulate dendritic morphology and long-lasting cocaine mediated synaptic plasticity (Schratt et al., 2006; Magill et al., 2010; Giusti et al., 2014). For example, overexpression of miR-125b induced formation of long thin spines, while reduced miR-125b increases the width of dendritic spines. (Edbauer et al., 2010). Thus, reduced miR-125b levels in the NAc by cocaine treatment may regulate dendritic spine formation. In addition, PARP-1 expression in NAc after chronic cocaine administration was shown to modulate dendritic plasticity via targeting sidekick-1 (SDK1; Scobie et al., 2014; Scobie, 2015). Therefore, miR-125b alone or by upregulating PARP-1 expression may regulate dendritic spine structure that plays important role in the behavioral response to cocaine addiction.

The rewarding and reinforcing effects of cocaine are mediated primarily by dopaminergic neurotransmission 
(Kuhar et al., 1991). Cocaine inhibits reuptake of dopamine by binding to DAT (Beuming et al., 2008) resulting in an increased levels of extracellular dopamine that stimulates reward pathways in the brain (Kalivas, 2007). In addition, mice that express a cocaine insensitive DAT variant do not elevate extracellular dopamine levels as compared to wild type mice and do not exhibit cocaineinduced reward (O'Neill et al., 2014; Wu et al., 2014). Since DAT is central to cocaine action, we probed whether binding of cocaine to DAT is essential for the downregulation of miR-125b. To test this, we used the DAT blocker- nomifensine (Ferris et al., 2012). Nomifensine serves as an excellent probe to study DAT, since this compound binds to a pocket on DAT that is believed to be not targeted by cocaine (Tella et al., 1997). Due to this differential binding, the neuroadaptive molecular changes induced by nomifensine, have been suggested to cause limited abuse potential compared to cocaine (Tella et al., 1997; Jones et al., 1995). For example, upregulation of DAT in caudate putamen and NAc was observed only with cocaine but not with nomifensine (Jones et al., 1995). This was also substantiated in our studies, wherein cocaine exposure resulted in the downregulation of miR-125b in DAT expressing cells while nomifensine had no effect (Fig. 5D). These properties of nomifensine enabled us to specifically demonstrate that binding of cocaine to DAT is critical for the downregulation of miR-125b. We observed that pretreatment of nomifensine to dopaminergic neuronal cells, abrogated both cocaine's effect on miR-125b expression (Fig. 5E), and cocaine-induced enhancement of PARP-1 protein expression (Fig. 5F,G). We further confirmed the role of DAT in cocaine-induced downregulation of miR-125b, by using HEK-293T cells that stably express DAT and endogenously express miR-125b (Fig. 5B). Whether this dependence on DAT in a neuronal cell model will also be applicable in vivo and the DAT-dependent downregulation of miR-125b is dependent on increased levels of dopamine are currently being investigated. Nevertheless, it is plausible that the role of DAT on miR-125b/PARP-1 axis in the neuronal cells could be attributed to local variability in extracellular dopamine levels.

In conclusion, we have demonstrated a post-transcriptional mechanism of regulation of PARP-1 expression via miR-125b. The persistent downregulation of miR-125b in the NAc during acute and chronic cocaine treatment suggest the importance of this brain enriched miRNA in cocaine-induced response. Thus, understanding the biology of miR-125b may advance the cellular and molecular mechanisms of cocaine addiction and reward.

\section{References}

Anderson EM, Self DW (2017) It's only a matter of time: longevity of cocaine-induced changes in dendritic spine density in the nucleus accumbens. Curr Opin Behav Sci 13:117-123. CrossRef

Barr TL, Conley YP (2007) Poly(ADP-ribose) polymerase-1 and its clinical applications in brain injury. J Neurosci Nurs 39:278-284. Medline

Bartel DP (2004) MicroRNAs: genomics, biogenesis, mechanism, and function. Cell 116:281-297. Medline
Bartel DP (2009) MicroRNAs: target recognition and regulatory functions. Cell 136:215-233. CrossRef Medline

Beuming T, Kniazeff J, Bergmann ML, Shi L, Gracia L, Raniszewska K, Newman AH, Javitch JA, Weinstein H, Gether U, Loland CJ (2008) The binding sites for cocaine and dopamine in the dopamine transporter overlap. Nat Neurosci 11:780-789. CrossRef

Blaho K, Logan B, Winbery S, Park L, Schwilke E (2000) Blood cocaine and metabolite concentrations, clinical findings, and outcome of patients presenting to an ED. Am J Emerg Med 18:593598. CrossRef

Chandrasekar V, Dreyer JL (2009) microRNAs miR-124, let-7d and miR-181a regulate cocaine-induced plasticity. Mol Cell Neurosci 42:350-362. CrossRef Medline

Chandrasekar V, Dreyer JL (2011) Regulation of MiR-124, Let-7d, and MiR-181a in the accumbens affects the expression, extinction, and reinstatement of cocaine-induced conditioned place preference. Neuropsychopharmacology 36:1149-1164. CrossRef

Chao J, Nestler EJ (2004) Molecular neurobiology of drug addiction. Annu Rev Med 55:113-132. CrossRef Medline

Chen CL, Liu H, Guan X (2013) Changes in microRNA expression profile in hippocampus during the acquisition and extinction of cocaine-induced conditioned place preference in rats. J Biomed Sci 20:96. CrossRef

Chen S-M, Chou W-C, Hu L-Y, Hsiung C-N, Chu H-W, Huang Y-L, Hsu H-M, Yu J-C, Shen C-Y (2015) The Effect of MicroRNA-124 Overexpression on Anti-Tumor Drug Sensitivity. Gonzalez P, ed. PLoS ONE 10(6):e0128472. CrossRef

Cohen-Armon M, Visochek L, Katzoff A, Levitan D, Susswein AJ, Klein R, Valbrun M, Schwartz JH (2004) Long-term memory requires polyADP-ribosylation. Science 304:1820-1822. CrossRef Medline

Doetsch M, Gluch A, Poznanović G, Bode J, Vidaković M (2012) YY1-binding sites provide central switch functions in the PARP-1 gene expression network. PLoS One 7:e44125. CrossRef Medline

Doura MB, Unterwald EM (2016) MicroRNAs modulate interactions between stress and risk for cocaine addiction. Front Cell Neurosci 10:125. CrossRef

Edbauer D, Neilson JR, Foster KA, Wang CF, Seeburg DP, Batterton MN, Tada T, Dolan BM, Sharp PA, Sheng M (2010) Regulation of synaptic structure and function by FMRP-associated microRNAs miR-125b and miR-132. Neuron 65:373-384. CrossRef

Eipper-Mains JE, Kiraly DD, Palakodeti D, Mains RE, Eipper BA, Graveley BR (2011) microRNA-Seq reveals cocaine-regulated expression of striatal microRNAs. RNA 17:1529-1543. CrossRef

Ferris MJ, Calipari ES, Mateo Y, Melchior JR, Roberts DC, Jones SR (2012) Cocaine self-administration produces pharmacodynamic tolerance: differential effects on the potency of dopamine transporter blockers, releasers, and methylphenidate. Neuropsychopharmacology 37:1708-1716. CrossRef

Fontan-Lozano A, Suarez-Pereira I, Horrillo A, del-Pozo-Martin Y, Hmadcha A, Carrion AM (2010) Histone $\mathrm{H} 1$ poly[ADP]-ribosylation regulates the chromatin alterations required for learning consolidation. J Neurosci 30:13305-13313. CrossRef

Giusti SA, Vogl AM, Brockmann MM, Vercelli CA, Rein ML, Trumbach D, Wurst W, Cazalla D, Stein V, Deussing JM, Refojo D (2014) MicroRNA-9 controls dendritic development by targeting REST. Elife 3. CrossRef

Ha HC, Snyder SH (2000) Poly(ADP-ribose) polymerase-1 in the nervous system. Neurobiol Dis 7:225-239. CrossRef Medline

Hartfield EM, Yamasaki-Mann M, Ribeiro Fernandes HJ, Vowles J, James WS, Cowley SA, Wade-Martins R (2014) Physiological characterisation of human iPS-derived dopaminergic neurons. PLoS One 9:e87388. CrossRef

Hassa PO, Hottiger MO (1999) A role of poly (ADP-ribose) polymerase in NF-kappaB transcriptional activation. Biol Chem 380:953959. CrossRef Medline

Heard K, Palmer R, Zahniser NR (2008) Mechanisms of acute cocaine toxicity. Open Pharmacol J 2:70-78. CrossRef Medline

Heyer MP, Kenny PJ (2015) Corticostriatal microRNAs in addiction. Brain Res 1628:2-16. CrossRef Medline 
Hollander JA, Im HI, Amelio AL, Kocerha J, Bali P, Lu Q, Willoughby D, Wahlestedt C, Conkright MD, Kenny PJ (2010) Striatal microRNA controls cocaine intake through CREB signalling. Nature 466:197-202. CrossRef Medline

Im HI, Hollander JA, Bali P, Kenny PJ (2010) MeCP2 controls BDNF expression and cocaine intake through homeostatic interactions with microRNA-212. Nat Neurosci 13:1120-1127. CrossRef Medline

Jonas S, Izaurralde E (2015) Towards a molecular understanding of microRNA-mediated gene silencing. Nat Rev Genet 16:421-433. CrossRef Medline

Jones SR, Garris PA, Wightman RM (1995) Different effects of cocaine and nomifensine on dopamine uptake in the caudateputamen and nucleus accumbens. J Pharmacol Exp Ther 274: 396-403. Medline

Kalivas PW (2007) Neurobiology of cocaine addiction: implications for new pharmacotherapy. Am J Addict 16:71-78. CrossRef Medline

Karch SB, Stephens B, Ho CH (1998) Relating cocaine blood concentrations to toxicity-an autopsy study of 99 cases. J Forensic Sci 43:41-45. CrossRef

Krishnakumar R, Kraus WL (2010) PARP-1 regulates chromatin structure and transcription through a KDM5B-dependent pathway. Mol Cell 39:736-749. CrossRef Medline

Kuhar MJ, Ritz MC, Boja JW (1991) The dopamine hypothesis of the reinforcing properties of cocaine. Trends Neurosci 14:299-302. Medline

Lagos-Quintana M, Rauhut R, Yalcin A, Meyer J, Lendeckel W, Tuschl T (2002) Identification of tissue-specific microRNAs from mouse. Curr Biol 12:735-739. Medline

Le MT, Teh C, Shyh-Chang N, Xie H, Zhou B, Korzh V, Lodish HF, Lim B (2009a) MicroRNA-125b is a novel negative regulator of p53. Genes Dev 23:862-876. CrossRef Medline

Le MT, Xie H, Zhou B, Chia PH, Rizk P, Um M, Udolph G, Yang H, Lim B, Lodish HF (2009b) MicroRNA-125b promotes neuronal differentiation in human cells by repressing multiple targets. Mol Cell Biol 29:5290-5305. CrossRef

Lee KW, Kim Y, Kim AM, Helmin K, Nairn AC, Greengard P (2006) Cocaine-induced dendritic spine formation in D1 and D2 dopamine receptor-containing medium spiny neurons in nucleus accumbens. Proc Natl Acad Sci USA 103:3399-3404. CrossRef

Lin S, Gregory RI (2015) MicroRNA biogenesis pathways in cancer. Nat Rev Cancer 15:321-333. CrossRef Medline

Lupo B, Trusolino L (2014) Inhibition of poly(ADP-ribosyl)ation in cancer: old and new paradigms revisited. Biochim Biophys Acta 1846:201-215. CrossRef Medline

Magill ST, Cambronne XA, Luikart BW, Lioy DT, Leighton BH, Westbrook GL, Mandel G, Goodman RH (2010) microRNA-132 regulates dendritic growth and arborization of newborn neurons in the adult hippocampus. Proc Natl Acad Sci USA 107:20382-20387. CrossRef

Mantri CK, Pandhare Dash J, Mantri JV, Dash CC (2012) Cocaine enhances HIV-1 replication in CD4+ T cells by down-regulating MiR-125b. PLoS One 7:e51387. CrossRef Medline

Meloche J, Le Guen M, Potus F, Vinck J, Ranchoux B, Johnson I, Antigny F, Tremblay E, Breuils-Bonnet S, Perros F, Provencher S, Bonnet S (2015) miR-223 reverses experimental pulmonary arterial hypertension. Am J Physiol Cell Physiol 309:C363-C372. CrossRef

Mittleman RE, Wetli CV (1984) Death caused by recreational cocaine use. An update. JAMA 252:1889-1893. Medline

Morales J, Li L, Fattah FJ, Dong Y, Bey EA, Patel M, Gao J, Boothman DA (2014) Review of poly (ADP-ribose) polymerase (PARP) mechanisms of action and rationale for targeting in cancer and other diseases. Crit Rev Eukaryot Gene Expr 24:15-28. CrossRef

Nestler EJ (2004) Historical review: molecular and cellular mechanisms of opiate and cocaine addiction. Trends Pharmacol Sci 25:210-218. CrossRef
Nestler EJ (2004) Molecular mechanisms of drug addiction. Neuropharmacology 47 [Suppl 1]:24-32. CrossRef Medline

Oei SL, Griesenbeck J, Schweiger M, Babich V, Kropotov A, Tomilin N (1997) Interaction of the transcription factor YY1 with human poly(ADP-ribosyl) transferase. Biochem Biophys Res Commun 240:108-111. CrossRef Medline

O'Neill B, Tilley MR, Han DD, Thirtamara-Rajamani K, Hill ER, Bishop GA, Zhou FM, During MJ, Gu HH (2014) Behavior of knock-in mice with a cocaine-insensitive dopamine transporter after virogenetic restoration of cocaine sensitivity in the striatum. Neuropharmacology 79:626-633.

Peretti FJ, Isenschmid DS, Levine B, Caplan YH, Smialek JE (1990) Cocaine fatality: an unexplained blood concentration in a fatal overdose. Forensic Sci Int 48:135-138. CrossRef

Picciotto MR (2010) Neuroscience: microRNA knocks down cocaine. Nature 466:194-195. CrossRef Medline

Rehmsmeier M, Steffen P, Höchsmann M, Giegerich R (2004) Fast and effective prediction of microRNA/target duplexes. RNA 10: 1507-1517. CrossRef

Ritz MC, Lamb RJ, Goldberg SR, Kuhar MJ (1987) Cocaine receptors on dopamine transporters are related to self-administration of cocaine. Science 237:1219-1223. Medline

Schiewer MJ, Knudsen KE (2014) Transcriptional roles of PARP1 in cancer. Mol Cancer Res 12:1069-1080. CrossRef Medline

Schratt GM, Tuebing F, Nigh EA, Kane CG, Sabatini ME, Kiebler M, Greenberg ME (2006) A brain-specific microRNA regulates dendritic spine development. Nature 439:283-289. CrossRef

Scobie KN (2015) Poly(ADP)-ribose polymerase-1 inhibitors as a potential treatment for cocaine addiction. CNS Neurol Disord Drug Targets 14:727-730. Medline

Scobie KN, Damez-Werno D, Sun H, Shao N, Gancarz A, Panganiban $\mathrm{CH}$, Dias C, Koo J, Caiafa P, Kaufman L, Neve RL, Dietz DM, Shen L, Nestler EJ (2014) Essential role of poly(ADP-ribosyl)ation in cocaine action. Proc Natl Acad Sci USA 111:2005-2010. CrossRef Medline

Sievers F, Wilm Dineen AD, Gibson T, Karplus J, Li K, Lopez W, McWilliam R, Remmert H, Soding MJ, Thompson JD, Higgins DG (2011) Fast, scalable generation of high-quality protein multiple sequence alignments using Clustal Omega. Mol Syst Biol 7:539.

Tella SR, Ladenheim B, Cadet JL (1997) Differential regulation of dopamine transporter after chronic self-administration of bupropion and nomifensine. J Pharmacol Exp Ther 281:508-513. Medline

Van Dyke C, Barash PG, Jatlow P, Byck R (1976) Cocaine: plasma concentrations after intranasal application in man. Science 191: 859-861. CrossRef

Verdone L, La Fortezza M, Ciccarone F, Caiafa P, Zampieri M, Caserta M (2015) Poly(ADP-ribosyl)ation affects histone acetylation and transcription. PLoS One 10:e0144287. CrossRef Medline

Wang SH, Liao XM, Liu D, Hu J, Yin YY, Wang JZ, Zhu LQ (2012) NGF promotes long-term memory formation by activating poly(ADP-

ribose)polymerase-1. Neuropharmacology 63:1085-1092. CrossRef Medline

Wei H, Yu X (2016) Functions of PARylation in DNA damage repair pathways. Genomics Proteomics Bioinformatics 14:131-139. CrossRef Medline

Wu H, O'Neill B, Han DD, Thirtamara-Rajamani K, Wang Y, Gu HH (2014) Restoration of cocaine stimulation and reward by reintroducing wild type dopamine transporter in adult knock-in mice with a cocaine-insensitive dopamine transporter. Neuropharmacology 86:31-37. CrossRef

Xu LF, Wang J, Lv FB, Song Q (2013) Functions of microRNA in response to cocaine stimulation. Genet Mol Res 12:6160-6167. CrossRef Medline

Zaniolo K, Desnoyers S, Leclerc S, Guérin SL (2007) Regulation of poly(ADP-ribose) polymerase-1 (PARP-1) gene expression through the post-translational modification of Sp1: a nuclear target protein of PARP-1. BMC Mol Biol 8:96. CrossRef 